\title{
LA PROPRIETÀ FONDIARIA DALLA BONIFICA INTEGRALE DI ARRIGO SERPIERI ALLA RIFORMA AGRARIA DI ANTONIO SEGNI. DIRITTO E POLITICA NELLE RIFLESSIONI DI MARIO BRACCI TRA PROPRIETÀ PRIVATA E SOCIALIZZAZIONE DELLA TERRA
}

\author{
LAND OWNERSHIP FROM ARRIGO SERPIERI'S COMPLETE \\ RECLAMATION TO ANTONIO SEGNI'S AGRARIAN REFORM. \\ LAW AND POLITICS IN MARIO BRACCI'S REFLECTIONS BETWEEN \\ PRIVATE OWNERSHIP AND THE SOCIALIZATION OF THE LAND
}

\section{Floriana Colao}

Università degli Studi di Siena

\begin{abstract}
English: In Giangastone Bolla's Program for the Review of Agricultural Law (1922) land ownership was a testing ground for the «modern transformations of property law» - on which Enrico Finzi - primarily with the "social function». Bolla observed the shift from ownership to the company; asserted that the link between agriculture and the state required the scholar of agricultural law to undertake the «social and economic reconstruction of the country". In view of the "social function" Arrigo Serpieri - since 1923 Undersecretary of State for Agriculture - promoted various legislative measures for the «integral reclamation»; the policy for agriculture was linked to the organization of the corporate state in fieri (Brugi, Arcangeli). The 1933 Consolidated Law (TU) aimed at the rehabilitation of the land to increase its productivity and improve the conditions of the peasants with land transformations of public interest, with possible expropriation of large estates and forced execution of reclamation works on private lands; from 1946 the Consolidated Law of 1933 will be considered an indication for the agrarian reform (Rossi Doria, Segni). In the first Congress of Agricultural Law, (Florence 1935), Maroi, Pugliatti, Serpieri, D’Amelio, Bolla, Ascarelli, Calamandrei discussed some issues, in the first place agricultural law as a factual experience, linked to rural life, irreducible to a uniform juridical order; hence the 'long duration' of the Jacini Report on the various agricultural Italy. In view of the civil codification, the jurists noted the insufficiency of the individualistic system; placed the request for rules focused on the good and not on the subjects, up to the overcoming of the distinction between public and private law. The most illustrious Italian jurists intervened in the volume promoted by the Confederation of agricultural workers; The Fascist conception of property expressed the detachment from the liberal conception - with an emphasis on land ownership based on work (Ferrara, Panunzio) - and held firm to private initiative (Filippo Vassalli). Bolla reiterated the particularity of land ownership between the corporate system and the civil code project, "a private institution, aided and regulated by the State", with the owner "moderator et arbiter» of his own initiative. In the civil code of 1942, land ownership made sense of the
\end{abstract}

* Italian Review of Legal History, 7 (2021), n. 10, pagg. 323-376

* https://riviste.unimi.it/index.php/irlh/index

* ISSN 2464-8914 - DOI 10.54103/2464-8914/16892. Articolo pubblicato sotto Licenza CC-BY. 
dynamic aspect of productive activity, without contemplating the "social function» as a «new property right» (Pugliatti, Vassalli, D’Amelio)

After the fall of the fascist regime, the struggles in the countryside forced Minister Gullo to plan agrarian contracts and regulate the occupation of uncultivated lands, with multiyear concessions to the occupying peasants; the De Gasperi award compensated the sharecroppers. The different economies of the 'different agrarian Italy' did not recommend a uniform agrarian reform; the reorganized political parties aimed at the distribution of expropriated lands, compensation to the private owner, without damaging the right of ownership. The initial action of the State to erode the large estates, with special reform bodies, had as its purpose the enhancement of small peasant property (Segni, Bandini). To combine private property and social interest in Constitution, Mortati motivated his proposal for a «constitutional statute»; Fanfani asked for «an article that speaks expressly of the land». The large estate was the most urgent but divisive issue, between Di Vittorio, who asked for its "abolition», and Einaudi for its "transformation», a choice that was imposed in the name of the various 'rural Italy'; the proposal for a rule intended to hinder large landholdings was not accepted. Article 44 of the Constitution provided for a law to impose "obligations and constraints on private land ownership», in order to "achieve rational land use and fair social relations». Bolla appreciated the choice of «transforming individual property into social property»; Vassalli wrote about a non-original «handbook for resolving the agrarian problem». In the project of the Minister for Agriculture Segni - who managed to launch a contested agrarian reform - art. 44 dictated tasks to the "future legislator»; the Sila law of 21 May 1950, the excerpt law of 21 October 1950 for particularly depressed areas, the bills on agricultural contracts were discussed in the Third Congress of Agricultural Law and in the first International Conference, promoted by Bolla, with interventions by Bassanelli, Segni, Capograssi, Pugliatti, Santoro Passarelli, Mortati, Esposito. Work was considered the architrave of land ownership, "a continually changing right, which must be modeled on social needs» (Bolla).

In this context, the theoretical-practical, juridical-political reflection of Mario Bracci, professor of administrative law in Siena, rector, also in charge of teaching agricultural law, is interesting. Representative of the $\mathrm{PdA}$ at the National Council in the Agriculture Commission, Bracci proposed to write a «book on the socialization of the land", never published; the personal archive offers a wealth of notes previously unpublished on the subject. Bracci defined land ownership as the lintel of agricultural law and a crossroads of private and public law, between land reclamation laws, civil codification, art. 44 of the Constitution, the agrarian reform, understood as a «problem of justice». From Fascism to the Republic, Bracci grasped technical continuities and ideological discontinuities in the structure of landed property, considered to be of constitutional significance, in referring to the person, "the conditions of the person are inextricably linked to those of landed property". As a scholar and professor of administrative law and agricultural law, since July 1944 Bracci intended to respond to the conflict in the countryside, mediating between «public purposes of agricultural production and the needs of social justice»; proposed «adequate legal forms which are forms of public law».

Keywords: History of agricultural law in the twentieth century; Landed property; Mario Bracci; Landed property and socialization of the lands 
(1922) la proprietà fondiaria era banco di prova delle «moderne trasformazioni del diritto di proprietà» - su cui Enrico Finzi - in primo luogo con la "funzione sociale». Nell'azienda agraria Bolla osservava inoltre lo spostamento dalla proprietà all'impresa; asseriva che il legame tra l'agricoltura e lo Stato imponeva allo studioso del diritto agrario l'impegno per la "ricostruzione sociale ed economica del paese». In vista della «funzione sociale» Arrigo Serpieri - dal 1923 sottosegretario di Stato all'Agricoltura - promuoveva diversi provvedimenti legislativi per la «bonifica integrale»; la politica per l'agricoltura si legava all'organizzazione dello Stato corporativo in fieri (Brugi, Arcangeli). Il Testo unico del 1933 mirava al risanamento della terra per aumentarne la produttività e migliorare le condizioni dei contadini con trasformazioni fondiarie di pubblico interesse, con possibili espropri di latifondi ed esecuzione coatta di lavori di bonifica su terre private; dal 1946 il Testo unico del 1933 sarà considerato una indicazione per la riforma agraria (Rossi Doria, Segni). Nel primo Congresso di diritto agrario, (Firenze 1935), Maroi, Pugliatti, Serpieri, D’Amelio, Bolla, Ascarelli, Calamandrei discutevano alcune questioni, in primo luogo il diritto agrario come esperienza fattuale, legato alla vita rurale, irriducibile ad un ordine giuridico uniforme; da qui la lunga durata della 'fortuna' dell Relazione Jacini sulle diverse Italie agrarie. In vista della codificazione civile, i giuristi rilevavano l'insufficienza dell'impianto individualistico; ponevano l'istanza di norme incentrate sul bene e non sui soggetti, fino al superamento della distinzione tra diritto pubblico e privato. I più illustri giuristi italiani scrivevano nel volume promosso dalla Confederazione dei lavoratori dell'agricoltura; La Concezione fascista della proprietà esprimeva il distacco dalla concezione liberale - con l'accento sulla proprietà della terra fondata sul lavoro (Ferrara, Panunzio) - e teneva ferma l'iniziativa privata (Filippo Vassalli). Bolla ribadiva la particolarità della proprietà fondiaria tra ordinamento corporativo e progetto del codice civile, «istituto a base privata, aiutato e disciplinato dallo Stato», con il titolare "moderator et arbiter» della propria iniziativa. Nel codice civile del 1942 la proprietà fondiaria aveva senso dell'aspetto dinamico dell'attività produttiva, senza contemplare la «funzione sociale» come «nuovo diritto di proprietà» (Pugliatti, Vassalli, D’Amelio).

Dopo la caduta del regime fascista le lotte nelle campagne imponevano al ministro Gullo di progare i contratti agrari e regolare l'occupazione delle terre incolte, con concessioni pluriennali ai contadini occupanti; il lodo De Gasperi indennizzava i mezzadri. Le differenti economie delle 'diverse Italie agrarie' sconsigliavano una riforma uniforme (Rossi Doria, Serpieri); i riorganizzati partiti politici miravano alla ripartizione delle terre espropriate e ad indennizzi al proprietario privato, senza lesioni del diritto di proprietà. L'iniziale azione dello Stato ad erosione del latifondo, con appositi Enti di riforma, aveva per scopo la valorizzazione della piccola proprietà contadina (Segni, Bandini). Per coniugare proprietà privata ed interesse sociale nella Costituzione Mortati motivava la sua proposta di "statuizione costituzionale»; Fanfani chiedeva «un articolo che parli espressamente della terra». Il latifondo era la questione più urgente ma divisiva; Di Vittorio ne chiedeva l' «abolizione» ed Einaudi la "trasformazione», scelta che si imponeva in nome delle diverse 'Italie rurali'; non si recepiva la proposta di una norma intesa ad ostacolare le grandi proprietà terriere. L'articolo 44 della Costituzione prevedeva una legge a imporre «obblighi e vincoli alla proprietà terriera privata», al fine di "conseguire il razionale sfruttamento del suolo ed equi rapporti sociali». Bolla apprezzava la scelta di «trasformare la proprietà individuale in proprietà sociale»; Vassalli scriveva di un non originale "prontuario di risoluzione del problema agrario». Nel progetto del Ministro per l'agricoltura Segni - che riusciva a far varare una contrastata riforma agraria - l'art. 44 dettava compiti al «legislatore 
futuro»; la legge Sila 21 Maggio 1950, la legge stralcio del 21 Ottobre 1950 per le zone particolarmente depresse, i progetti di legge sui contratti agrari erano discussi nel Terzo congresso di diritto agrario e nel primo Convegno internazionale, promosso da Bolla, con interventi di Bassanelli, Segni, Capograssi, Pugliatti, Santoro Passarelli, Mortati, Esposito. Il lavoro era considerato l'architrave della proprietà della terra, «diritto continuamente cangiante, che deve modellarsi sui bisogni sociali» (Bolla).

In questo quadro è interessante la riflessione teorico-pratica, giuridico-politica di Mario Bracci, docente di diritto amministrativo a Siena, rettore, incaricato anche dell'insegnamento di diritto agrario. Rappresentante del PdA alla Consulta nazionale nella Commissone agricoltura, Bracci si proponeva di scrivere un «libro sulla socializzazione della terra», mai pubblicato; l'Archivio personale offre una mole di appunti finora inediti sul tema. Bracci collocava nella storia la proprietà della terra, che aveva senso nel «lavoro»; la definiva architrave del diritto agrario e crocevia di diritto privato e pubblico, tra le leggi di bonifica, la codificazione civile, l'art. 44 della Costituzione, la riforma agraria, intesa come «problema di giustizia». Dal fascismo alla Repubblica Bracci coglieva continuità tecniche e discontinuità ideologiche nell'assetto dell'istituto di rilevanza costituzionale, «le condizioni della persona sono indissolubilmente legate a quelle della proprietà fondiaria». Da studioso e docente di diritto amministrativo e diritto agrario dal luglio 1944 Bracci intendeva rispondere al conflitto nelle campagne, mediando tra «fini pubblici della produzione agraria e le esigenze della giustizia sociale»; proponeva «forme giuridiche adeguate e che sono forme di diritto pubblico».

Parole chiave: Storia del diritto agrario nel Novecento; proprietà fondiaria; Mario Bracci; proprietà fondiaria e socializzazione delle terre

Sommario : 1. Mario Bracci giurista del Novecento tra diritto e politica. - 2. Mario Bracci 'agrarista'. - 3. La proprietà fondiaria nel regime fascista. - 4. II problema agrario alle origini della democrazia in Italia. - 5. La socializzazione delle terre per Mario Bracci. - 6 . La proprietà terriera nell'art. 44 della Costituzione. - 7. Un compito per il «legislatore futuro»: la proprietà fondiaria nella riforma agraria. - 8. Appunti dalle lezioni di diritto agrario del professor Bracci.

\section{Mario Bracci giurista del Novecento tra diritto e politica}

Mario Bracci nacque a Siena il 12 febbraio 1900; forte della passione politica di giurista, avrebbe condiviso il destino intellettuale di una "generazione del Novecento ${ }^{1}$, nel viaggio attraverso l'Italia liberale, fascista, repubblicana. Dopo gli studi al Ginnasio Liceo Guicciardini Bracci si iscrisse alla Facoltà di giurisprudenza, dove ebbe maestri Guido Zanobini, docente di diritto amministrativo, Piero Calamandrei, docente di diritto processuale civile e ordinamento giudiziario, il penalista Eugenio Florian. Esonerato dalle tasse nel 1919, per aver prestato ser-

\footnotetext{
${ }^{1}$ Abbreviazioni: Archivio di Stato di Siena = ASS; Archivio storico Università di Siena = AsuS. Vivarelli, 2008, pp. 157 ss; Colao 2015, pp. 245-266.
} 
vizio in guerra, Bracci si laureò il 21 Aprile 1921, con la votazione di 110 e lode²; la tesi di laurea, La proposta nel diritto amministrativo, sarebbe stata pubblicata nel $1961^{3}$. Incaricato di diritto amministrativo a Sassari nel 1924, perfezionatosi ad Heidelberg nel 1925-1926, nel 1927 Bracci vinse il concorso, bandito nell'ateneo sardo, e dal 1930 fu chiamato come ordinario a Siena ${ }^{4}$, dove avrebbe anche lavorato nello studio paterno. Coinvolto in incidenti col fascismo locale, membro del partito repubblicano del comitato senese d'opposizione all'indomani del delitto Matteotti, Bracci fu tra i firmatario del 'Manifesto Croce'. Nel 1948 il giurista senese avrebbe ricordato con rimpianto,

io ero giovanissimo nel 1920, 1921, 1922, ma allora avevo tanto entusiasmo addosso che quello che non perdonerò mai al fascismo è di avermi costretto per vent'anni ad una sterile posizione critica ${ }^{5}$.

Come Calamandrei, nell'impegno scientifico e didattico Bracci è parso esercitare l' "ufficio del giurista nello Stato autoritario», senza sottrarsi alla necessaria 'collaborazione' col regime, in virtù della "ermeneutica della reticenza» ${ }^{6}$. La sensibilità politica del giurista senese era dunque riflessa nello studio del 1925 su un tema particolarmente sentito, Le pensioni di guerra, opera originale per l'attribuzione "del principio della responsabilità oggettiva dello Stato». II libro L'Italia, la Santa sede e Città del Vaticano nel 1931 negava alla nuova realtà la natura statuale, in considerazione dell' «unità intangibile» dello Stato italiano». Quanto alle opere specialistiche, La proposta in diritto amministrativo e Dell'atto complesso in diritto amministrativo, incentrato sulla volontà, erano contributi rilevanti entro l'amministrativistica italiana'. Nel 1937 a nome della Facoltà giuridica senese Bracci inviava al guardasigilli Grandi le adesive Osservazioni sul progetto preliminare del codice di procedura civile, firmate assieme al processualcivilista Alessandro Raselli. La codificazione era vista in continuità con quanto "proclamato ormai da tempo dalla migliore dottrina processuale [che] risponde pienamente alle caratteristiche fondali dello Stato fascista»; l'omaggio al regime era legato al ribadire la richiesta di "garanzie di giustizia»" ${ }^{8}$ Su invito di Calamandrei - artefice del codice di procedura civile del $1940^{9}$ - nel 1941 Bracci pubblicava un profondo saggio sul senso del processo civile, ponendo il «problema politico delle gua-

\footnotetext{
${ }^{2}$ AsuS, XII Bb 47, Mario Bracci. Fascicolo personale $n$. 1137. Una biografia di Bracci, forte della documentazione archivistica in Moscadelli, 2020.

${ }^{3}$ Bracci, 1961.

${ }^{4}$ AsuS, Libretti delle Lezioni XIV, C. 15: Mario Bracci, Diritto amministrativo.

${ }^{5}$ Bracci 1981a, pp. 339-340.

${ }^{6}$ Cianferotti, 2008, p. 259.

${ }^{7}$ Cianferotti, 2007a, pp. 703 ss; Id., 2007b, pp. 153-207; Id., 2013, pp. 325-327; Id., 2015, pp. 221-244.

${ }^{8}$ Bracci, Raselli, 1937, p. 234, su cui Colao, 2014, pp. 190-191.

${ }^{9}$ Bindi, Colao (edd.), 2021.
} 
rentigie della giustizia», che, oltre "l'ordinamento dei tribunali ordinari», pareva avere una dimensione costituzionale, nel dipendere da «fattori ben più profondi e complessi» ${ }^{10}$.

Subito dopo la liberazione di Siena Bracci chiedeva di aderire alla sezione senese del Partito d'azione, accompagnando la richiesta con quella dell'istituzione di un giurì d'onore. Intendeva dimostrare come prive di fondamento certe voci «anonime e calunniose», giunte al Partito, circa suoi profitti derivanti dall'adesione al regime fascista, non precisati scritti di propaganda per l'Italia di Mussolini, l'amicizia personale con Delacroix - non negata - ed altri gerarchi, l'ostacolare l'applicazione delle sanzioni contro il fascismo in città. Il giurì - composto dal comunista Ranuccio Bianchi Bandinelli, da Raselli, dall'avvocato Bruno Delle Piane - riconosceva a Bracci «atteggiamenti politici coerenti»; la frase sostituiva quella nella minuta circa l' «antifascista sicuro e convinto» ${ }^{11}$. Eletto rettore, il 26 novembre 1944 Bracci teneva un solenne Discorso in occasione della riapertura dell'Università, alla presenza del commissario regionale del governo militare alleato, delle autorità cittadine, del corpo accademico. I fattori storici del fascismo italiano ed il loro superamento indicavano la necessità di 'fare i conti' col passato come condizione per la costruzione di una nuova Italia; di contro all'argomento sul regime impostosi solo con la violenza, il Discorso affrontava con decisione il tema scomodo del consenso, per cui pareva una «leggenda» la narrazione di pochi squadristi, capaci di imporre per vent'anni un regime con la sola forza del manganello. II rettore parlava di responsabilità storica, morale, politica, prima che penale, di chi, "re in testa e classe dirigente, aveva consegnato l'Italia al fascismo"; ma il ventennio non appariva solo effetto del disfacimento delle classi dirigenti liberali, della reazione di «classe» davanti ai «vessilli proletari», oltretutto agitati senza sbocco politico. Bracci ripensava ai giovani del primo dopoguerra, irretiti dalle "promesse di rinnovamento»; ammetteva "noi credemmo». Invitava i ventenni presenti a non avvilirsi, perché «unici innocenti»; per l'avvenire prospettava le parole d'ordine «libertà» e «solidarietà», cardini di una "società dove unica misura del merito sia il lavoro». Senza dare spazio alla retorica sottolineava "di deliberato proposito ho evitato la parola antifascismo. La negazione deve discendere come conseguenza logica da ciò che affermiamo» ${ }^{12}$.

Nella stagione della costruzione della democrazia Bracci affrontava da giurista civile i temi più complessi, con interventi rivolti all'opinione pubblica, oltre la 'cittadella' degli specialisti. In primo luogo rifletteva sullo Stato e l'amministrazione, ripensando i cardini della giuspubblicistica tra Otto e Novecento, le "formule», lo Stato persona tra tutte, che ora parevano "astratte»,

\footnotetext{
${ }^{10}$ Bracci, 1941, pp. 165-211.

${ }^{11}$ ASS, Archivio Mario Bracci 74, ins. 2, doc. 47.

${ }^{12}$ Bracci, 1981b, p. 54.
} 
Lo Stato assume l'aspetto di una persona mitologica [...] che siede in trono dominando i cittadini genuflessi [...] che vive una sua vita del tutto distaccata da quella della società che la compone.

A questo Stato «astratto come noi lo consideriamo, uomini della strada o giuristi», Bracci opponeva il modello anglosassone, incentrato sulla responsabilità personale di chi si fosse distaccato dalle regole nell'esercizio delle "funzioni pubbliche». L'ordine post-fascista pareva dover essere rifondato su uno stile di correttezza assoluta tra individuo e autorità, pena il rischio che, «pur gettato via il fascio littorio», la pubblica amministrazione finisse per essere ancora incardinata nei binari dello «Stato straordinariamente incanaglito» del ventennio. Bracci, sempre meno interessato ad analisi concettuali dei temi affrontati, metteva in discussione il tradizionale metodo scientifico nella determinazione «dei principi della vita dello Stato",

noi giuristi a forza di lavorare su nozioni teoriche che assomigliano alle formule chimiche dei libri di fisiologia, perdiamo di vista che l'amministrazione è lo Stato vivo operante che attua continuamente i propri fini ${ }^{13}$.

Discutendo i lavori della Commissione Forti, l'amministrativista senese paventava una "legge dottrinaria sui principi generali», destinata a finire "polverosa in un angolo»; auspicava una dimensione sociocentrica, e non statocentrica, del "diritto amministrativo», "ancora quello del tempo fascista», così come lo Stato appariva il grande malato di sempre, con le leggi espressione di «patologia e non fisiologia». Bracci ricordava che schemi «perfetti dal punto di vista tecnico giuridico [...] in omaggio alla più pura pedanteria tedesca», rischiavano la fine del "pallone di carta velina», se "dietro le formule giuridiche non c'era nulla» ${ }^{14}$. In una fase di «incertezza sulle nozioni di pubblico e privato», di fronte al "peso sociale dell'individuo», Bracci chiamava il legislatore ad incoraggiare la "socialità», con un vasto programma di riforme per un ordine giuridico democratico, tutto da costruire, per «47 milioni di Italiani $»^{15}$.

Tra le questioni da affrontare per la «realtà italiana», nel dicembre 1945 l'amministativista pensava al «problema regionale». Ai "partiti democratici, che si affermano oggi regionalisti», Bracci indicava il rischio che lo "Stato democratico», in via di costruzione, potesse essere «indebolito col dare tutto il favore agli enti minori»; definiva inoltre "demagogia negare il costume politico italiano, per ragioni storiche favorevole allo Stato centralizzato". II "selfgovernment dei popoli anglosassoni» e lo "Stato federale» parevano modelli impraticabili per il "punto nero» del regionalismo in Italia, gli squilibri tra nord e sud del "disgraziato paese»; in particolare il «problema finanziario» appariva d'ostacolo al «decen-

\footnotetext{
${ }^{13}$ Bracci, 1981c, p. 33.

${ }^{14}$ Bracci, 1951, pp. 163 ss.

${ }^{15}$ Bracci, 1981d, pp. 164-168.
} 
tramento costituzionale». Bracci proponeva allora un «decentramento amministrativo», poggiante sulla "saggia finanza, una delle massime glorie della democrazia». Al proposito auspicava il rafforzamento del «senso di responsabilità degli amministratori locali»; il «problema regionale» era inquadrato nella tensione per una «etica pubblica, fondata sulla partecipazione alla vita delle istituzioni» ${ }^{16}$.

Nel 1945 Bracci era nominato per il Partito d'Azione componente della Consulta nazionale, ed assegnato alla Commissione agricoltura e alimentazione ${ }^{17}$. Era nominato ministro del Commercio estero nel primo ministero De Gasperi, cui offriva un contributo importante nell'esporre «nella mia qualità di giurista e non di quella di membro del governo, secondo il suo desiderio, il mio punto di vista sulle questioni del referendum».

Nell'incertezza del quadro costituzionale per l'attesa troppo prolungata del risultato ufficiale della votazione, Bracci 'salvava la repubblica', coniando una felice formula, il passaggio ope legis dal re al presidente del Consiglio dell'esercizio delle funzioni, e non dei poteri, di capo dello Stato. La vivace Storia di una settimana avrebbe ricordato che "le parole hanno molta importanza, ma coloro che non sono giuristi stentano ad apprezzare queste sfumature»; per Bracci le parole del diritto avevano risparmiato al "popolo» i rischi di una "guerra civile» e il fallimento della "speranza, anzi certezza repubblicana»" ${ }^{18}$.

Alla vigilia dell'elezione del capo provvisorio dello Stato Bracci rifletteva sull'alternativa tra un presidente «notaio o custode della Repubblica», scegliendo la seconda opzione, pensata come correttivo all'azione dei "grandi partiti di massa» - che apparivano ben diversi dal "partito parlamentare» dell'Italia liberale e dal Partito nazionale fascista - «sostanzialmente arbitri della volontà dell'Assemblea [...] portati a svalutare un poco gli organi costituzionali». Bracci assegnava al presidente ben altro compito che la «funzione rappresentativa»,

punto di equilibrio di queste forze costituzionali [...] difesa e rafforzamento della Repubblica [...] forza suprema forza conciliatrice e coordinatrice presso il presidente del Consiglio, i ministri e i capipartito [...] per la difesa della Repubblica. Altro che funzione rappresentativa! ${ }^{19}$.

Dopo lo scioglimento del Partito d'Azione Bracci aderiva al Partito socialista, divenendo consigliere giuridico di Nenni. Nel 1947 rifiutava un seggio in Parlamento "per motivi ideali [...] gli italiani ci credono poco, io invece ci credo»" era eletto membro dell'Alta corte per la Regione siciliana. In quell'anno Bracci affrontava su II Ponte il primo scandalo politico-affaristico dell'Italia repubblicana; davanti all'«ondata fangosa» si poneva alla ricerca di un ordine giuridico per la

\footnotetext{
${ }^{16}$ Bracci, 1981e, pp. 133-147.

${ }^{17}$ La Consulta nazionale 1948, 25 Settembre 1945- I Giugno 1946, Roma, 1948, p. 78.

${ }^{18}$ Bracci, 1981f, p. 213; sulla formula come «capolavoro» cfr. Branca, 1960, p. 161.

${ }^{19}$ Bracci, 1981g, p. 195.

${ }^{20}$ Fonti in Cardini, 2001, p. 57.
} 
«corruzione politica», colta come una delle più gravi criticità per la «nascente democrazia», di cui parevano gioire i «nostalgici dell'autocrazia ${ }^{21}$. La riflessione sui «partiti attuali» era legata ai mutamenti del quadro politico, dalle speranze riposte all'indomani della Liberazione nelle "tendenze di libera lotta democratica», al pericolo, nel 1948, di una Repubblica «privilegio o monopolio di un partito o di un gruppo di partiti politici» ${ }^{22}$. Della Resistenza, sottratta al «patriottismo di partito», Bracci celebrava la "solidarietà nazionale»; poneva il tema dell' «impedire alle tendenze politiche di divenire fazione e sopraffare lo Stato ${ }^{23}$. Da socialista riformista il giurista senese affermava che la «sostanza sociale della repubblica italiana, ancora informe e indefinita», doveva essere realizzata in virtù delle "grandi riforme di struttura», non convincenti sul solo piano teorico, ma da valutare alla «prova dei fatti» ${ }^{24}$.

Bracci era un intellettuale e politico di primo piano a Siena; da rettore fin dal 1944 promuoveva il notevole sviluppo dell'ateneo, soprattutto con la progettazione del Policlinico universitario. Consigliere comunale socialista, dal 1951 al 1955 offriva contributo decisivo alla formulazione del piano regolatore della città, che avrebbe sottratto il centro storico alla speculazione ${ }^{25}$. L'elezione di Bracci a giudice costituzionale maturava in una particolare congiuntura politica, la Presidenza di Gronchi, il governo presieduto da Antonio Segni, conosciuto dall'amministrativista senese negli anni dell'insegnamento a Sassari; Bracci, 'uomo della Sinistra', era eletto con i voti del Partito socialista, comunista, di parte dei democristiani. L'inedito Crisi della Corte costituzionale?, del dicembre 1958, affrontava il prisma di temi-problemi legati alla Consulta, gli ostacoli politici posti all'entrata in funzione - Bracci riconosceva a Segni il merito di «vero artefice» - il «contrasto» con gli altri organi costituzionali, alla Corte sottoposti, l'identità di organo sovrano non superiorem recognoscens, piuttosto che di giurisdizione speciale; pendeva la questione dell'insindacabilità degli interna corporis acta, poi risolta con sentenza 9/1959. Bracci era incaricato dalla Corte di proporre regole per la formazione delle norme processuali per i giudizi pendenti; contribuiva alle prime fondamentali pronunce nel trienno 1956-1959. Crisi della Corte costituzionale? sottolineava il rilievo del controllo di costituzionalità, condizione per tagliare finalmente «rami secchi o marciti della tradizione poliziesca e fascista». Bracci percepiva che il ruolo della Consulta era fondamentale nella costruzione della democrazia; da qui la tensione far conoscere l'attività dell'organo costituzionale all'opinione pubblica, nell'auspicio che «gli uomini della strada» finissero per apprezzarlo più del «Parlamento ${ }^{26}$.

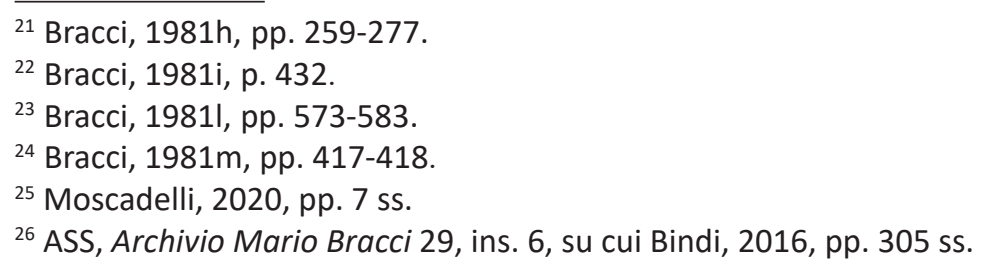


Alla fine del 1958 la Lettera «confidenziale» a Gronchi non mancava di illustrare le criticità della Repubblica, in primo luogo il Parlamento ridotto ad «organo di registrazione e d'esecuzione di indirizzi politici dei partiti [...] incapaci di assicurare il buon funzionamento e la difesa delle istituzioni». A correttivo dell' «immobilità della macchina legislativa» e "continue crisi di governo» Bracci affidava al capo dello Stato una funzione di indirizzo politico diverso da quello del presidente del consiglio, espressione di una maggioranza pro tempore. Tematizzava una «responsabilità della direzione politica del paese in misura assai superiore a quella attuale». Bracci si diceva consapevole di avere l' «orologio avanti ${ }^{27}$; moriva il 15 Maggio 1959, compianto su II Ponte da Paolo Barile, allora collega a Siena, come amico ed «autentico uomo di Stato, che avesse questa nostra acerba Italia poco democratica e scarsamente repubblicana» ${ }^{28}$.

\section{Mario Bracci 'agrarista'}

Nel ricordo di Raselli alla fine degli anni Trenta Bracci aveva acquistato la Certosa di Pontignano per "l'amore per la coltivazione dei campi», per "l'agricoltura toscana, che fioriva nella zona (e che Egli sviluppò notevolmente) ${ }^{29}$. Nella Siena appena liberata Bracci scriveva di voler aderire alla sezione senese del Partito d'Azione per un interesse particolare, che coniugava diritto e politica,

mi era noto che il partito d'azione propugnava un programma di riforme sociali assai radicale per ciò che riguarda la proprietà fondiaria [...] e io stesso sto scrivendo un libro sulla socializzazione della terra, nel quale è sostenuto un progetto assai audace ${ }^{30}$.

Anche se il giurista senese non ha pubblicato un «libro sulla socializzazione della terra", l'Archivio personale consente di conoscere una mole di appunti, finora anche inediti, specchio di una grande passione civile e privata, durata negli anni, tutt'altro che marginale nella riflessione dello studioso e docente di diritto amministrativo. All'indomani della liberazione di Siena, Bracci vedeva nel "lavoro» l'architrave dell'ordine giuridico agrario, prima che il principio trovasse sbocco normativo nella Costituzione ${ }^{31}$. La riflessione teorica andava di pari passo con l'impegno politico; nella tensione a portare il Partito d'Azione dalla città alla campagna quattro Discorsi, tenuti tra l'estate e l'autunno 1945 in provincia di Siena ${ }^{32}$, contenevano spunti ripresi nel denso II problema giuridico della terra ${ }^{33}$,

\footnotetext{
${ }^{27}$ Bracci, 1981n, p. 745.

${ }^{28}$ Barile, 1959, p. 473.

${ }^{29}$ Raselli, 1962.

${ }^{30}$ ASS, Archivio Mario Bracci 74, ins. 2, doc. 47.

${ }^{31}$ ASS, Archivio Mario Bracci 49, ins. Affare la socializzazione della terra. Grazie all'amico Stefano Moscadelli per la riproduzione.

${ }^{32}$ Bracci, 2020, pp. 193-232.

${ }^{33}$ Bracci, 1945, pp. 189-200, su cui Bindi, 2015, pp. 281-282.
} 
pubblicato nel 1945 su II Ponte, su richiesta di Calamandrei. Anche come risposta alle agitazioni mezzadrili, erano iscritti nel circuito tra diritto e politica Un opuscolo per i contadini ${ }^{34}$ ed un polemico intervento sulla stampa senese ${ }^{35}$. Dal 1951 al 1955 Bracci era incaricato anche dell'insegnamento di diritto agrario ${ }^{36}$; la passione civile per la materia improntava gli Appunti dalle Lezion ${ }^{37}$.

Nelle tante pagine di Bracci la proprietà della terra era considerata in prospettiva storica, in un campo di tensione con la funzione sociale, crocevia di diritto privato e pubblico definito dalle leggi di bonifica, la codificazione civile, l'art. 44 della Costituzione, la tanto attesa e contrastata riforma agraria, intesa da Bracci come "problema di giustizia»" ${ }^{38}$. Dal fascismo alla Repubblica il giurista senese coglieva continuità tecniche e discontinuità ideologiche nell'assetto della proprietà fondiaria, istituto di rilevanza costituzionale; un appunto sull' «evoluzione strettamente individuale della proprietà romana», pietra angolare della codificazione civile moderna, asseriva "le condizioni della persona sono indissolubilmente legate a quelle della proprietà fondiaria ${ }^{39}$.

In tema di agricoltura il Partito d'Azione aveva parole d'ordine incentrate su «la terra ai contadini ${ }^{40}$; Bracci assumeva posizioni minoritarie, come nel caso della difesa della mezzadria, nel Senese sistema sociale prima che contratto agrario $^{41}$. In vista della riforma agraria Bracci condivideva l'opzione, maggioritaria tra i giuristi e i politici, di scongiurare una legislazione uniforme per quel che l'ancora citatissima Relazione Jacini aveva definito le diverse 'Italie agrarie'. II giurista senese cercava piuttosto l'occasione per colmare lo squilibrio nel regime della proprietà fondiaria, nel segno 'riformista' della trasformazione del latifondo e redistribuzione delle terre ai coltivatori diretti, tensioni che avrebbero trovato sbocco normativo nella Costituzione. In termini esemplari in un Discorso a Montepulciano del 4 Novembre 1945 l'azionista Bracci dichiarava che «non è nostra intenzione [...] abolire la proprietà privata», «questione di libertà $»^{42}$. Fin dalla liberazione Bracci maturava una riforma agraria in sintonia con quella di Antonio Segni, dalla fine del 1944 sottosegretario del Ministero dell'Agricoltura e foreste, ministro dal 14 Luglio $1946^{43}$. Nel 1958 Crisi della Corte costituzionale? apprez-

\footnotetext{
${ }^{34}$ Bracci, 1981o, pp. 97 ss.

${ }^{35}$ ASS, Archivio Mario Bracci 49, ins. 2.

${ }^{36}$ AsuS, XII Bb 47, Mario Bracci. Fascicolo personale n. 1137.

${ }^{37}$ Bracci, 1954-1955.

${ }^{38}$ Bracci, 1945, p. 190.

${ }^{39}$ ASS, Archivio Mario Bracci 49, ins. 21, La proprietà della terra.

${ }^{40} \mathrm{Cfr}$. Sommaruga, 1944, pp. 130 ss.

${ }^{41}$ Su Ernesto Rossi, favorevole all'abolizione immediata della mezzadria, e Manlio Rossi Doria, più gradualista cfr. De Luna, 1997, pp. 198 ss.

42 Bracci, 2020, pp. 226, 230.

${ }^{43}$ Su Segni ministro, artefice della riforma agraria cfr. Rescigno, 2006, pp. 167 ss; Mattone, 2016; Mura, 2017.
} 
zava che le "leggi agrarie» avessero superato il controllo di costituzionalità ${ }^{44}$; nel 1959, quando il miracolo economico scandiva ormai «la fine dell' Italia rurale» ${ }^{45}$, Bracci intestava il merito della riforma a Segni, che non avrebbe però potuto seguirne l'attuazione. Era infatti costretto a passare al Ministero dell'istruzione, lasciando quello dell'Agricoltura e Foreste a Fanfani, criticato da Bracci,

è riuscito a trasformare, nel ricordo dei 'possidentes', la tua riforma agraria, attuata, in un innocente esperimento di agronomia rispetto alle temute riforme rovinose del segretario fiorentino, che in realtà, lungi dall'attuarle, non le ha mai neppure progettate ${ }^{46}$.

\section{La proprietà fondiaria nel regime fascista tra corporativismo e tradizione civilistica}

La «funzione sociale» ${ }^{47}$ della proprietà pareva entrare nel discorso giuridico dalle porte di quella "fondiaria» fin dal Programma di Bolla per la Rivista di diritto agrario, che nel 1922 tematizzava il legame dell'istituto con il «concetto attuale dello Stato» ed indicava il ruolo dell'agrarista, «il dovere di portare un contributo anche modesto al progresso della civiltà e del diritto, alla ricostruzione sociale ed economica del paese ${ }^{48}$.

Nel segno dell'autonomia del diritto agrario - che già Calamandrei avrebbe intestato a Bolla ${ }^{49}$ - il fatto economico 'produzione' irrompeva al centro dell'ordine giuridico patrimoniale, con lo spostamento dalla proprietà all'azienda agraria. Fin dal 1922 Bolla coglieva il tramonto dell'élite sociale architrave dell'Italia liberale, i proprietari terrieri, che avevano preteso di essere ceto generale; osservava infatti

la costituzione di una classe sempre più distinta ed organizzata direttamente interessata al fenomeno produttivo» [...] accanto al fondo prende forma e si differenzia l'azienda agraria, centro di attività economica e sociale ${ }^{50}$.

La proprietà fondiaria pareva dunque terreno d'elezione di quelle che Enrico Finzi definiva le «moderne trasformazioni del diritto di proprietà» ${ }^{51}$, nel segno

\footnotetext{
${ }^{44}$ ASS, Archivio Mario Bracci 29, ins. 6

${ }^{45}$ Cardini, 2006, p. 11.

${ }^{46}$ La lettera di Bracci a Segni del 20 Febbraio 1959 in Moscadelli, 2019, p. 411.

${ }^{47}$ In generale Macario, Miletti, 2015.

${ }^{48}$ Bolla, 1922, p. 4. Sul giurista cfr. Grossi, 2000, pp. 239 ss; Irti, 2002, pp. 179 ss; Iannarelli, 1999, pp. 632-680; Costato, 2013, pp. 274-276; Gentile, 2018, pp. 49 ss.

${ }^{49}$ Nell'anniversario dei trenta anni della 'Rivista persona' di Bolla Calamandrei ricordava la tensione a «studiare ravvicinati e coordinati, per quanto tecnicamente distinti e eterogenei, tutti gli aspetti giuridici [della] disciplina giuridica autonoma»; Calamandrei, 1952, p. 239.

${ }^{50}$ Bolla, 1922, p. 4.

${ }^{51}$ Finzi, 1923, p. 271. Il 20 Gennaio 1945 nella Firenze liberata Finzi avrebbe auspicato la cancellazione dei «codici fascisti»; in seguito avrebbe colto nella funzione sociale della
} 
'weimariano' del diritto che obbliga, dovere sociale. Anche di fronte alle occupazioni di terre del primo dopoguerra Filippo Vassalli osservava sulla Rivista di diritto agrario che il recente "tumultuoso legiferare», con l'intervento statuale in economia, riguardava in gran parte la proprietà fondiaria; parlando all'Accademia dei Georgofili prospettava un'alternativa, tra il «potenziare la volontà de' privati (con i limiti connaturati al diritto)», o piegare "la libertà di ciascuno [...] ai fini posti dallo Stato ${ }^{52}$. Nella Relazione al Congresso di bonifiche venete, promosso nel 1922 da Silvio Trentin, Arrigo Serpieri sottolineava la necessità di trasformare i contadini in proprietari, in quanto produttori agricoli; la proprietà fondiaria pareva irriducibile a diritto assoluto, per rivestire una «funzione sociale» ${ }^{53}$. Sottosegretario di Stato all'Agricoltura dal 1923, l'agronomo di Bologna promuoveva una serie di provvedimenti all'insegna della "bonifica integrale ${ }^{54}$; la legge 18 Maggio 1924, Sulle trasformazioni fondiarie di pubblico interesse disponeva lo svuotamento idraulico delle terre malsane e il loro recupero agricolo. Nel segno del romagnosiano «incivilimento" Serpieri puntava a potenziare il movimento ruralista in virtù dell'inclusione di contadini in nuovi poderi, per 'sbracciantizzare' le campagne e realizzare l'autarchia della produzione agricola. L'intervento dello Stato attraverso istituzioni pubbliche comportava la creazione di Consorzi tra proprietari, in vista di una struttura sociale della proprietà fondiaria, con l'obbiettivo ambizioso di tutelare 'integralmente' il territorio; la politica per l'agricoltura trovava un punto di intersezione con l'organizzazione dello Stato corporativo in fieri ${ }^{55}$. Al proposito Biagio Brugi osservava che il diritto agrario era terreno d'elezione per la «ricomposizione della società politica in classi e corporazioni» ${ }^{56}$; Argeo Arcangeli celebrava l' «armonica combinazione tra capitale e lavoro $»^{57}$.

Anche Serpieri collocava il diritto agrario in quello pubblico; spiegava all'Accademia dei Georgofili - di cui dal 1926 era presidente - che "gli agronomi del Consesso più antico e prestigioso d'Europa» non «amarono mai la libertà economica

proprietà delineata dalla Costituzione una continuità con la concezione corporativa. Sul civilista cfr. Grossi, 2008a, p. 19.

${ }^{52}$ Vassalli, 1960, pp. 323 ss; indicazioni in Ferri, 2013, pp. 2022-2025.

${ }^{53}$ Serpieri, 1922. Sul Convegno cfr. Bolchini, 2016, pp. 129 ss. Serpieri, docente di economia agraria della Scuola superiore di Milano, era chiamato a Firenze nell'Istituto superiore forestale. Sottosegretario all'agricoltura, poi alla bonifica integrale, nel 1934 era estromesso dagli incarichi di governo per l'opposizione dei latifondisti siciliani ad un disegno di esproprio. Rettore dell'ateneo fiorentino fino alla liberazione, durante il provvedimento di epurazione era invitato a collaborare alla Commissione economica del Ministero della Costituente; partecipava al dibattito politico e giuridico sulla riforma agraria. Indicazioni in Di Sandro, 2015; Misiani, 2018; Di Sandro, Monti, 2020.

${ }^{54}$ Serpieri, 1929, pp. 17 ss; illustrazione e bilancio di un decennio di attuazione della legislazione in Serpieri, 1937; Serpieri, 1947.

${ }^{55}$ Serpieri, 1925. Sul tema cfr. Tavilla, 2004.

${ }^{56}$ Brugi, 1928, p. 184. Sul tema cfr. Stolzi, 2007, p. 219.

${ }^{57}$ Arcangeli, 1930, pp. 129 ss. 
astrattamente», ma la intesero protesa al «progresso» della Toscana e poi della "nazione italiana» ${ }^{58}$. Con "richiami storici» Serpieri illustrava pertanto il cuore vitale de La proprietà fondiaria nel regime fascista, sostenendo che «nulla vi sia di assoluto nella proprietà della terra», irriducibile alla formula "questa è mia», perchè «strumento di produzione». Al proposito citava i rilevi mossi già da Pellegrino Rossi all'impianto individualista del code civil e le osservazioni di Bonfante e Ghino Valenti sull'analogo codice civile del 1865. Serpieri asseriva di condividere le «opinioni liberali» dei Soci georgofili del Settecento, sorte per liberare la terra dai «vincoli feudali»; affermava che, nonostante il tramonto del canone "giusnaturalistico» dell' «individuo anteriore allo Stato», la proprietà privata non era in discussione, pena privare il "proprietario di ciò che con l'opera ha prodotto", «negargli la libertà personale». D'altro canto sosteneva che la proprietà privata fondiaria aveva carattere «esclusivamente sociale»; indicava il «latifondismo e polverizzazione» come "deviazioni dall'impiego più redditizio della terra», fulcro della tensione del fascismo a "ruralizzare l'Italia», come anche l'Inghilterra pareva 'tornare alla terra', contro i «veleni urbani». Serpieri chiariva dunque che la politica agraria del regime non voleva la «disastrosa e mortifera produzione di Stato», ma era ispirata al "dovere dello Stato d'intervenire», laddove il proprietario non fosse stato in grado di garantire un alto reddito del bene produttivo. La proprietà fondiaria era indicata come diversa dall' «io egoista» dell'individualismo proprietario ottocentesco, sostituito con l'«io corporativo», l'«io italiano» ${ }^{59}$.

La legge 24 Dicembre 1928 - detta di Mussolini - confermava l'indirizzo rurale della legislazione; nelle parole di Serpieri - dal 1929 sottosegretario alla bonifica integrale - l'architrave della politica agraria del regime complicava l'impianto individualistico della codificazione civile liberale. L'agronomo insisteva sulla necessità di «espropriare i proprietari esistenti», se inattivi, "sostituendoli con altri aventi caratteristiche più desiderate», in grado di "comprendere il limite dell'interesse nazionale ${ }^{60}$. Le retoriche del regime sul 'ruralismo', sull'homo rusticus, gli slogans mussoliniani, che avevano il loro cuore vitale sul lavoro nella terra, la scenografica battaglia del grano, destinate ad attirare il consenso delle masse contadine ${ }^{61}$, erano iscritte nella tensione - ben esplicitata da Serpieri - a fare della mezzadria la forma di collaborazione per eccellenza tra "capitalista e lavoratore», rectius la "famiglia del lavoratore», vista la politica per le "famiglie numerose, disciplinate sotto l'autorità di un capo». La Carta della mezzadria - varata su Progetto della Confederazione dei sindacati fascisti dell'agricoltura - sanciva la natura associativa del contratto nel segno del diritto agrario corporativo. II sostanziale riconoscimento del controllo padronale incontrava però le critiche dello

\footnotetext{
${ }^{58}$ Serpieri, 1927a, pp. XVII-XXXII.

${ }^{59}$ Serpieri, 1927b, pp. 62-81.

${ }^{60}$ Serpieri, 1929, pp. 17 ss. Analogamente Commissione di studi giuridici della Confederazione nazionale fascista degli agricoltori, 1930.

${ }^{61} \mathrm{Cfr}$. Canguilhem, 2007.
} 
stesso Serpieri, inteso a promuovere l'accesso dei contadini alla proprietà ${ }^{62}$.

II Testo unico 13 Febbraio 1933 intendeva la bonifica integrale come processo di risanamento della terra, per aumentarne il rendimento economico e migliorare le condizioni dei contadini in virtù di trasformazioni fondiarie di pubblico interesse, con possibilità di esproprio dei latifondi ed esecuzione coatta di lavori di bonifica su fondi privati; nel 1934 Serpieri era allontanato dal governo per i contrasti con i latifondisti siciliani, ostili all'esproprio. Nel 1938 Manlio Rossi Doria legava «il concetto dell'integralità della bonifica» alle "trasformazioni fondiarie», in primo luogo la quotizzazione del latifondo, vista in continuità con le misure del dopoguerra, il "celebre decreto Visocchi», l'istituzione dell'Opera nazionale per $\mathrm{i}$ combattenti, i progetti dei socialisti e dei popolari, e poi, dopo la marcia su Roma, il lavoro del Serpieri nella Commissione di studi tecnici ed economici presso la Federazione dei Consorzi agrari. Rossi Doria apprezzava l'idea di una «trasformazione», che seguisse "da caso a caso vie diverse», con carattere d'obbligatorietà «per vie modeste e progressive», con il coinvolgimento delle «forze del Mezzogiorno opportunamente sostenute ${ }^{63}$.

II Testo unico, che pareva avere un passato, sarà apprezzato nel futuro; nel 1947 Rossi Doria porrà il tema della «individuazione della proprietà», in vista di interventi «più intensivi», richiamando le scelte di Serpieri, «maestro degli economisti agrari», autore di una «legislazione eccellente $»^{64}$. Nel 1950 lo stesso Serpieri non ricorderà le norme del 1933 nei termini della "legge di Mussolini», ma del «risultato di oltre un cinquantennio di dura esperienza bonificatrice, che è gloria italiana $»^{65}$. A commento della riforma agraria, tra le «leggi speciali» Segni indicherà il T.U «sulla bonifica» come un modello per la "struttura giuridica della riforma fondiaria», dal momento che il legislatore del tempo aveva posto al proprietario "vincoli e limiti al potere di godere e disporre della proprietà», senza peraltro "toccare in alcun punto l'istituto» ${ }^{66}$.

All'indomani della bonifica Salvatore Pugliatti offriva un ampio contributo allo studio della riorganizzazione della proprietà terriera; ricostruiva le norme in tema di requisizioni ed occupazioni di terre durante la guerra e il primo dopoguerra, di trasformazioni fondiarie, della facoltà, accordata all'Opera Combattenti, di chiedere il trasferimento in sua proprietà di terreni soggetti ad obblighi ${ }^{67}$. Nel primo Congresso nazionale di diritto agrario, ospitato dai Georgofili nel 1935, Serperi celebrava la "Toscana culla e appassionato amore di istituti economici e giuridici di grandissimo rilievo per la vita rurale ${ }^{68}$. I numerosi interventi affrontavano un

\footnotetext{
${ }^{62}$ Cfr. Ascheri, 2011, p. 49; Passaniti, 2017, pp. 126 ss.

${ }^{63}$ Rossi Doria, 1956a, p. 229.

${ }^{64}$ Rossi Doria, 1956b, pp. 125 ss, Rossi Doria, 1956c, pp, 145 ss.

${ }^{65}$ Serpieri, 1957, p. 200.

${ }^{66}$.Segni, 1954a, p. 683.

${ }^{67}$ Pugliatti, 1954a, pp. 53 ss., 92 ss. Sul giurista messinese cfr. Grossi 2002, pp. 95 ss.

${ }^{68}$ Serpieri, 1935, p. 22. Sul «primo fondamentale congresso nazionale» cfr. lannarelli,
} 
prisma di temi-problemi legati all'agricoltura, la storicità del diritto agrario - nella densa Relazione di Fulvio Maroi ${ }^{69}$ - l'identità giuridica, poggiante sull'autonomia, l'intersezione con il corporativismo, la gestione produttiva del fondo, la distinzione tra proprietario e produttore, l'emersione dell'impresa - commerciale e agricola - in vista della sofferta scelta tra duplicazione o unificazione dei codici. Il guardasigilli e storico del diritto Arrigo Solmi evocava un "codice rurale», per "completare l'edificio della grandezza giuridica italiana»; al tempo stesso, "nel nuovo sistema corporativo italiano», poneva il tema della redazione di un "codice di tutta la produzione e del lavoro»" ${ }^{70}$. Anche Gaetano Azzariti - capo dell'Ufficio legilativo del Ministero - si soffermava sull'alternativa tra un "codice agrario, come da parecchi si auspica», o "un codice più vasto della produzione o del lavoro ${ }^{71}$. La questione era legata alla necessità di riconoscere al diritto agrario uno statuto autonomo; Mariano D’Amelio - presidente della Commissione legislativa per la riforma del codice di commercio - proponeva di affidare la materia alla consuetudine, specchio della struttura autentica dei rapporti sociali nelle campagne, da valorizzare perchè "refrattaria alla politica» ${ }^{72}$. L'idea era in sintonia con l'opera di Bolla, convinto dell'importanza di una raccolta nazionale delle consuetudini agrarie, dato l'ontologico «ritardo del diritto rispetto ai fatti della vita rurale» ${ }^{73}$.

Tra gli interventi al primo Congresso Pugliatti vedeva un terreno di incontro tra civilisti e agraristi nello studio del "fondo rustico, destinato ad essere coltivato a fruttificare, e quindi arricchire il paese». II giurista messinese asseriva che la «terra, più importante fattore di produzione in un paese eminentemente agricolo come il nostro", poteva sembrare "tipico bene consacrato esclusivamente alla proprietà dei privati». Osservava invece che lo "spirito corporativo» imponeva un "ponderato dosaggio tra interesse della collettività organizzata e dei singoli che ad essa appartengono», una "combinazione tra interesse pubblico e privato», introdotta nella legislazione speciale, che peraltro lasciava la «proprietà chiave di volta del nostro edificio sociale ${ }^{74}$. Finzi - vicino a Serpieri dai tempi del Circolo di cultura a Firenze - proponeva la distinzione tra proprietà e produzione agraria, mettendo in luce "varie forme di godimento effettivo", legate all' «appartenenza economica». Il senso di uno spazio privato non rilevava solo per l'intangibilità, ma per un facere, con una attività intesa alla «rilevanza produttiva dei beni». L'inte-

\footnotetext{
1999, p. 635.

${ }^{69}$ Maroi, 1935, pp. 27 ss. Sull'assertore del «diritto agrario come norma sociale», poggiante sulla «forza normativa dei fatti» e sulla «natura delle cose» cfr. Costato, 2013, pp. 1281-1283.

${ }^{70}$ Solmi, 1935, p. 245.

${ }^{71}$ Azzariti, 1935, pp. 144 ss.

72 D’Amelio, 1935, pp. 523 ss.

${ }^{73}$ Bolla, 1931, p. 606, su cui Grossi, 2016, pp. 7 ss.

${ }^{74}$ Pugliatti, 1935, pp. 185 ss.
} 
resse della produzione non implicava una "disciplina amministrativa dei beni»; la 'scandalosa' configurazione della proprietà come "potere discrezionale» consentiva la coesistenza del vincolo - il fine dell'attività individuale - e della libertà, nella scelta dei mezzi più idonei a ottenere il risultato produttivo, in un concorso attivo tra pubblico e privato, che a Finzi pareva iscritto nell'ordinamento corporativo. L'attenzione per l'«officina delle cose» comportava «rapporti capovolti: non più $i$ beni in funzione del soggetto, ma questo in funzione di quelli» ${ }^{75}$.

Tullio Ascarelli vedeva nel diritto agrario, «speciale», la "funzione di pioniere nella conquista di principi giuridici». La "politica dell'intevento dello Stato» ed il «postulato della prevalenza dei diritti e degli interessi della Nazione su quelli di individui o classi» sembravano affievolire la "tradizionale» distinzione tra pubblico e privato; il "fondo agrario» era indicato come profilo del passaggio dalla «considerazione prevalententemente individualistica» a quella dei "gruppi e di rapporti tra gruppi» ${ }^{76}$. Calamandrei definiva la "concezione patriarcale ed arcadica dell'agricoltura» della 'Toscanina' - radicata nel paese dai tempi dell' 'iconico' Pietro Leopoldo - anacronistica al tempo dei «consorzi, delle grandi affittanze, delle macchine e della bonifica integrale». L'impresa agraria era l'orizzonte del giurista fiorentino; gli «idilli georgici» della codificazione del 1865 apparivano lontani quanto «i frammenti del diritto romano, che di tali idilli sono stati i principi ispiratori». Il futuro artefice del codice di procedura civile del 1940 marcava la distanza dal 'mondo di ieri', l' «agricoltura dei nostri vecchi» ${ }^{77}$. Bolla ripeteva che, accanto al fondo, andava da tempo prendendo piede l'impresa agraria, connotata dal lavoro, con l'accento sui dati economici e sul valore normativo della natura delle cose; pareva antistorico leggere questa realtà nei termini della proprietà ex articoli 436 e seguenti del codice civile, pena un pericoloso scollamento tra economia e diritto ${ }^{78}$. Santoro Passarelli sosteneva che l'affitto rustico doveva affrancarsi dallo schema generico ed angusto della locazione, disciplinata dal codice civile del 1865; l'impianto individualistico non pareva appagante nel normare nuove questioni legate all'esercizio dell'agricoltura, le bonifiche, il credito agrario, le assicurazione sociali obbligatorie ${ }^{79}$.

In vista della codificazione la Confederazione fascista dei lavoratori dell'Agricoltura promuoveva un volume incentrato su La concezione fascista della proprietà, attratta nel campo del diritto pubblico in particolare da Sergio Panunzio ${ }^{80}$, mentre la civilistica si esercitava a marcare la distanza da quella «individualistica», che Francesco Ferrara definiva «liberale», «il proprietario della terra esercita[va]

\footnotetext{
${ }^{75}$ Finzi, 1935, pp. 158 ss. Il superamento della concezione soggettiva della proprietà della terra in Maiorca, 1934.

${ }^{76}$ Ascarelli, 1935, pp. 102 ss.

${ }_{77}$ Calamandrei, 1935, p. 357.

${ }^{78}$ Bolla, 1935, pp. 148 ss.

${ }^{79}$ Santoro Passarelli, 1935, pp. 406 ss.

${ }^{80}$ Panunzio, 1939, pp. 109 ss.; Chiarelli 1939, pp. 143 ss.; Pugliatti, 1939, pp. 161 ss.
} 
ugualmente la sua proprietà, sia che col lavoro la trasformasse in un campo fiorente, sia se la lasciasse abbandonata ai rovi e alle ortiche ${ }^{81}$.

Si imponeva un'altra prospettiva politica-giuridica, "lo sfruttamento della cosa e specialmente della terra deve essere fatto non in vista dell'interesse esclusivo del singolo, bensì in vista dell'interesse nazionale ${ }^{82}$.

Non mancavano interventi sulla continuità del diritto per l'agricoltura; Leicht comprendeva l'assetto della proprietà fondiaria nella "tradizione italiana» ${ }^{83}$. Pugliatti rinveniva nella legislazione speciale bellica e postbellica in materia di fondi rustici il riconoscimento dell' «interesse pubblico», legittimato dai movimenti rivendicativi nelle campagne. II giurista messinese asseriva che, nel momento in cui «la Nazione» mirava alla "conquista dell'autarchia economica», la "terra» - «che rappresenta per noi il più ricco serbatoio di risorse economiche» - doveva essere "sfruttata al massimo». Al tempo stesso chiariva che «il concetto di proprietà, finchè rimanga campo alla iniziativa privata, deve rimanere nella sua essenza inalterato ${ }^{84}$. Quanto alla "signoria del proprietario», Barassi metteva in luce un dualismo apparente tra "interesse individuale e pubblico» ${ }^{85}$. Balzarini osservava che la Carta del lavoro non parlava di proprietà, ma di «iniziativa privata nel campo della produzione», connotata dalla "funzione sociale» ${ }^{86}$. Filippo Vassalli riteneva invece questa formula superflua, dal momento che essa era propria di ogni potere riconosciuto dal diritto, ed oltrettutto rischiava di togliere "sicurezza e stabilità ad un rapporto giuridico di importanza fondamentale» ${ }^{87}$.

Il contributo di Bolla era particolarmente significativo nel rivendicare la peculiarità della proprietà fondiaria tra l'ordinamento corporativo e il progetto di codice civile. L'agrarista ripercorreva la storia, col rilevare, «nei paesi civili», "limitazioni crescenti» al "diritto assoluto di libertà» del suolo, di cui pareva emblema il Code rural del 1791. Segnalava anche la "Costituzione democratica di Weimar dell'11 Agosto 1919» e il coevo "Codice agrario dell'Urss», "che nega che la terra possa essere oggetto di proprietà privata». Con le parole di Mussolini Bolla sottolineava che "l'ordinamento corporativo fascista» rispettava invece la proprietà privata, «principio che completa la persona umana»; concludeva che "è un diritto, ma se è un diritto è anche un dovere». Bolla citava le pagine di Alfredo Rocco per definire una proprietà che produceva «ricchezza», col correggere l'«errore del socialismo», che riconduceva il lavoro nella terra a "questione di giustizia», quando era invece di "utilità e necessità sociale». Bolla asseriva che la proprietà fondiaria era un «istituto a base privata, disciplinato e aiutato dallo Stato», con il titolare

\footnotetext{
${ }^{81}$ Ferrara, 1939, pp. 271 ss.

82 Gatti, 1935, pp. 21 ss.

${ }^{83}$ Leicht, 1939, pp. 467 ss.

${ }^{84}$ Pugliatti, 1939, pp. 161 ss.

${ }^{85}$ Barassi, 1939, pp. 138 ss.

${ }^{86}$ Balzarini, 1939, pp. 83 ss.

${ }^{87}$ Vassalli, 1939, pp. 99 ss.
} 
«moderator et arbiter» della propria iniziativa, irriducibile a «funzionario sociale». Non riconduceva il «nuovo regolamento giuridico della proprietà fondiaria» alla sola «intensificazione dello stato sul processo economico» o a "fatti contingenti relativi al regime politico»; lo definiva "prodotto di una realtà storica, che si pone all'attenzione dei giuristi». In questo orizzonte Bolla affermava che il progetto di codice civile «non definisce cosa sia la proprietà fondiaria», per essere incentrato su un "criterio di astrattezza», per sottoporre allo stesso "regolamento la proprietà rustica e urbana», con una scelta che non pareva "corrispondere alla realtà creata dall'ordine corporativo ${ }^{88}$.

Nella voce per il Nuovo Digesto Bolla scriveva che la «terra» aveva creato istituti, che, a loro volta, avevano forgiato «ceti di persone caratteristiche e ben diverse nello spirito e nell'anima ${ }^{89}$. Da qui la presa d'atto della difficoltà a far sottostare il contratto agrario alle astratte simmetrie del diritto civile e l'apprezzamento per l'intervento dello Stato, con l'inserzione di «principi pubblicistici», architrave della «legge organica per l'agricoltura ${ }^{90}$. Bolla citava Serpieri per ribadire le peculiarità dell'impresa agraria rispetto a quella commerciale, a che il coltivatore diretto non rimanesse marginale rispetto al modello generale e che fosse tutelato il rapporto di lavoro prestato da manodopera estranea al nucleo familiare, prassi frequente nelle aziende agricole italiane ${ }^{91}$. Bolla, particolarmente vicino a Mussolini, pareva convincerlo dell'opportunità di un «codice agrario» o «legge organica per l'agricoltura ${ }^{92}$; nel 1942 Maroi avrebbe celebrato i venti anni della Rivista di diritto agrario ricordando il compito assolto dallo storico direttore nella politica per l'agricoltura del fascismo, che fin dal 1921 aveva indicato la «questione agraria» come il «problema socialmente ed economicamente più assillante ed angoscioso ${ }^{93}$.

Rispetto alla codificazione civile del 1865 quella varata nel 1942 contribuiva ad una modernizzazione dell'agricoltura; vi convergevano sia la tradizionale disciplina della proprietà fondiaria, sia la legislazione speciale, promossa dal regime. II capo II, Della proprietà fondiaria, indicava una particolare forma di proprietà privata, che aveva senso nell'aspetto dinamico dell'attività produttiva, irriducibile al profilo 'statico'. II dilemma tra funzione sociale e proprietà privata era il nodo più discusso, tra tradizione civilistica e corporativismo. Nel Commentario, diretto da Mariano D’Amelio, Pugliatti rivendicava per il giurista un «compito rigorosamente

\footnotetext{
${ }^{88}$ Bolla, 1939, pp. 551 ss; G.B. Funajoli 1939, pp. 511.

${ }^{89}$ Bolla, 1937, p. 273.

${ }^{90}$ Bolla, 1938, p. 89.

${ }^{91}$ Bolla, 1942 pp. 15 ss.

${ }^{92}$ Fonti in Gentile, 2018, pp. 53 ss.

${ }^{93}$ Maroi, 1942a, p. 2. II Programma agrario fascista definiva lo slogan la «terra a chi lavora» - avanzata nel primo dopoguerra dalle masse contadine - «formula semplice, demagogica e dannosa»; al tempo stesso prometteva una "poderosa preparazione del principio»; fonti in De Felice, 1961, p. 736.
} 
tecnico», col mettere da parte "polemiche» e «ideologie politico-sociali»; affermava che il codice non contemplava una «funzione sociale», in grado di «qualificare il nuovo diritto di proprietà $»^{94}$. Cesarini Sforza insisteva invece sulla funzione sociale e sugli interessi pubblici, iscritti nella azienda agraria, impensabile fuori dell'impresa ${ }^{95}$. Funaioli elencava i diversi soggetti e modelli societari, definiti dal lavoro,

agricoltore proprietario, usufruttuario, affittuario che si associa, dirigendolo, il lavoro del mezzadro, del colono, del soccidario [...] tanto si scosta dalla commerciale l'impresa agraria da avvicinarsi sensibilmente alla figura generica della 'piccola impresa' che il nuovo codice contempla ${ }^{96}$.

L'Accademia dei Georgofili ospitava diversi interventi sul codice civile; Bassanelli sottolineava la novità della coincidenza di proprietà e lavoro nella disciplina dei contratti agrari ${ }^{97}$. Maroi riconduceva le scelte codicistiche alla tradizione giuridica, con l'argomento che la prassi aveva talvolta preceduto l'organizzazione dell'impresa, con una configurazione legata alla 'materia' agricoltura, un «diritto dell'impresa agraria $)^{98}$. Anche se con l'unificazione dei codici era sfumata l'idea di una legge organica per l'agricoltura, il sottosegretario alla Giustizia Antonio Putzolu - dirigente dell'ufficio legislativo - pareva voler tranquillizzare soprattutto Bolla, a proposito di una futura legislazione, destinata

entro i principi e norme del codice [...] a offrire agli agricoltori italiani un quadro preciso delle norme emanate dal Regime per disciplinare le loro attività, fonte prima ed inesauribile del benessere e della potenza della nazione ${ }^{99}$.

Nel Novembre 1942 Putzolu ricordava che «nei rurali il Fascismo trovò i suoi militi», e che, in virtù dell'inquadramento nelle categorie del corporativismo, il regime aveva inteso "sollevare il contadino italiano alla stessa altezza delle altre categorie sociali», sostituendo l'impresa agricola alla «disciplina arcaica del fondo rustico» ${ }^{100}$. Nel febbraio 1943 Bolla illustrava i «due basilari presupposti enunciati dal codice Grandi: autonomia della materia agraria, proprietà privata della terra»; essi erano ricondotti all' «assetto rurale della civiltà italiana», nella sottolineatura del diritto «non astrazione», ma strumento di «giustizia migliore per i rurali, nell'accordo della proprietà col lavoro» ${ }^{101}$.

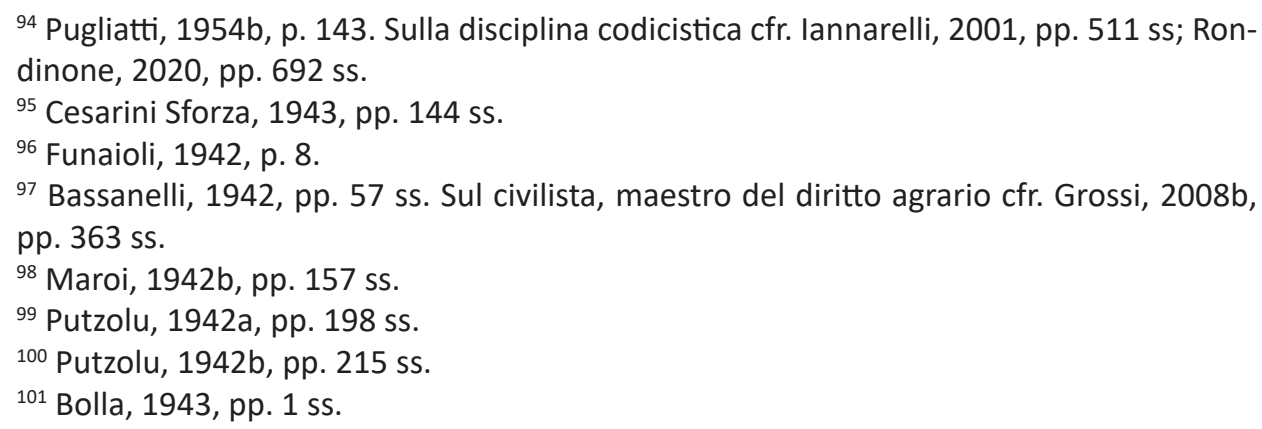




\section{Il problema agrario alle origini della democrazia in Italia}

Alla caduta del regime l'esaltazione della vita rurale e del 'tutti proprietari' non aveva ostacolato la proprietà assenteista, il latifondo, la miseria dei braccianti, l'esodo dalle campagne. II conflitto sociale, soffocato nella gabbia autoritaria, tornava a riproporsi negli stessi termini drammatici del primo dopoguerra, tra i fenomeni alle origini del fascismo. La soppressione delle Organizzazioni corporative non comportava la fine dell'impegno dello Stato a sostegno dell'iniziativa economica nelle campagne; la formula della funzione sociale della proprietà fondiaria continuava a circolare in vista di una futura riforma agraria. Per allentare la pressione sociale il ministro per l'agricoltura, il comunista Fausto Gullo, con il dl 3 giugno 1944 prorogava i contratti agrari; il dl 19 ottobre 1944 intendeva regolare l'occupazione di terre incolte o sequestrate ai fascisti con il prevedere concessioni pluriennali ai contadini associati ${ }^{102}$. Su Les temps modernes di Sartre Rossi Doria descriveva le diverse 'Italie agricole', negli stessi termini della Relazione Jacini; non intravedeva la "minaccia d'una rivoluzione agraria inevitabile», piuttosto la tensione a «modificare i rapporti rispetto alla proprietà fondiaria ed alla terra stessa» ${ }^{103}$. Per Rossi Doria i "contratti agrari» erano il principale problema, cui rispondere con una trasformazione della proprietà fondiaria a favore dei coltivatori, in virtù di consorzi ed enti di colonizzazione, organizzati in vista dell'interesse generale dell'agricoltura, "sotto il controllo democratico di tutti», non succubi di interessi particolari, in nome di una «malintesa autonomia» ${ }^{104}$. In particolare la risposta ai «problemi della mezzadria» era indicata come la «condizione indispensabile per il consolidamento della democrazia in Italia» ${ }^{105}$.

I temi dell'agricoltura si imponevano all'attenzione dei riorganizzati partiti politici ${ }^{106}$; l'azionista Rossi chiedeva una netta discontinuità con il fascismo, in una proposta che convergeva con la posizione socialista e comunista nel non dover «penalizzare la piccola proprietà ${ }^{107}$. Sereni asseriva che quest'ultima - cara non solo ai cattolici - era «il problema della terra»; indicava la "questione agraria» come l'architrave della "rinascita nazionale», e sosteneva la necessità di una riforma in grado di non porre più i lavoratori delle campagne sotto l'organizzazione, direzione e controllo delle "classi dominanti»"108. II decreto luogotenenziale 31 Luglio 1945 istituiva una Commissione economica, che operava una ricognizione delle limitazioni della proprietà fin dall'indomani della Grande guerra, delle bonifiche, della produzione agricola ${ }^{109}$. In risposta al dilagare delle lotte nelle

\footnotetext{
${ }^{102}$ Cfr. Mattone, 2016, p. 525.

${ }^{103}$ Rossi Doria, 1956d, pp. 295-301.

${ }^{104}$ Rossi Doria, 1956e, pp. 77 ss.

${ }^{105}$ Rossi Doria, 1956f, p. 321.

${ }^{106}$ Sommaruga, 1946, pp. 20 ss.

107 Rossi, 1945.

${ }^{108}$ Sereni, 1946, p. 226.

${ }^{109}$ Ministero della Costituente, 1947.
} 
campagne ed alle istanze di riscatto sociale il lodo De Gasperi affrontava le vertenze in tema di mezzadria, con la previsione di indennizzi per i coltivatori ${ }^{110}$. Il ministro per la Costituente, Pietro Nenni, auspicava uno studio degli indirizzi costituzionali in campo sociale ed economico da parte della Commissione Agricoltura - istituita nell'Ottobre 1945 e presieduta da Rossi Doria - per coniugare esigenze produttivistiche e sociali ${ }^{111}$. Nella Commissione Forti Umberto Terracini sosteneva la necessità di attuare la riforma agraria contestualmente alla Costituzione; Costantino Mortati proponeva di sancire un dovere costituzionale di coltivazione di fondi rustici ${ }^{112}$. Ad integrazione del decreto Gullo del 19 Ottobre 1944, nel Settembre 1946 il ministro Segni varava un provvedimento per la concessione ventennale delle terre incolte ai contadini ${ }^{113}$.

Nello «schema» presentato da Gian Giacomo Dell'Angelo per il Ministero della Costituente il lavoro risaltava come l'architrave del diritto per l'agricoltura, «non dono della natura, ma risultato di un sapiente e tenace lavoro degli uomini», poggiante sulla «complessa attività dell'imprenditore e dai rapporti che egli stringe con gli altri uomini legati alla terra da vincoli di lavoro». Si distinguevano i braccianti e i salariati fissi al Nord, i mezzadri al Centro "appoderato», i grandi affittuari del Po, i "gabellotti» siciliani, intenti a subaffittare ai "terraticanti», quotizzando la terra del "feudo», $i$ "grandi proprietari», in grado di gestire personalmente l'«azienda». Da qui le diverse «economie», quella latifondistica del Mezzogiorno, povera, quella più fiorente delle terre appoderate, la «grande azienda capitalistica». Per Dell'Angelo il «vario panorama agricolo» sconsigliava una «riforma su basi a carattere generale», ritenuta "semplicistica» e «incapace di giungere a qualsiasi risultato positivo». Il problema agrario ripeteva - con le parole di Rossi Doria - che «in Italia non possiamo in nessuna maniera impostare la riforma agraria secondo principi teorici generali». Le «variazioni nella distribuzione della proprietà» sembravano intese da taluni come strumento per realizzare «il più alto reddito globale nazionale», da altri una «maggiore perequazione della ricchezza e più alto livello di vita delle classi rurali». Dell'Angelo concludeva che le «tendenze politiche dei vari partiti» convergevano nel «riconoscimento del diritto di proprietà», «ripartizione delle terre espropriate», «diritto all'indennizzo del proprietario privato» ${ }^{114}$.

Nel 1946 un Comitato interministeriale - ne erano membri Segni, La Malfa, Gonella, Pacciardi - era incaricato di lavorare ad una «riforma fondiaria generale»; nel ricordo del segretario Mario Bandini - docente di economia agraria - alle riunioni interveniva spesso De Gasperi. Si discuteva di correzioni del latifondo, della creazione di nuove colonizzazioni, di appositi Enti di riforma e sviluppo del

\footnotetext{
${ }^{110}$ Rossi Doria, 1956, p. 340.

${ }^{111}$ Atripaldi, 2020, pp. 11 ss.

112 D'Alessio, 1978, pp. 93, 602.

${ }^{113}$ Mattone, 2016, pp. 525 ss.

${ }^{114}$ Dell'Angelo, 1946.
} 
territorio, di cooperative; lo scopo era la «formazione, rafforzamento e difesa della impresa familiare contadina». II punto chiave della discussione era la «intangibilità della struttura privata», assunto da rivedere, se la proprietà non rispondeva alle «necessità economiche». In risposta alle critiche degli espropri si argomentava che la «iniziale azione statale» era la premessa per una «successiva libera iniziativa di forze contadine», con "forme equilibrate e sane di proprietà privata e iniziativa individuale ${ }^{115}$. Dal canto suo Serpieri, esperto ascoltato anche in età repubblicana, interveniva all'Accademia dei Georgofili per raccomandare che la riforma agraria si risolvesse in un "movimento selettivo", non l'irruzione delle "masse di contadini verso il possesso terriero», piuttosto una redistribuzione della proprietà, sottratta ad incertezze sugli espropri. L'agronomo introduceva il tema di una riforma da realizzare in virtù di contratti agrari, tra contrattazione collettiva e accordi individuali, affinchè spettasse ai «migliori contadini la proprietà e conduzione della terra», senza negare la «ragion d'essere e benemerenze di un'attiva e indipendente borghesia agricola». Quanto all'azione dello Stato, Serpieri segnalava l'importanza di unità di direzione; raccomandava che gli Enti motore della riforma - non si risolvessero in organismi burocratici, bloccati dalle "consuete pastoie, lentezza, orrore della responsabilità»"

\section{La socializzazione della terra per Mario Bracci}

Nel 'Promemoria' sulla provincia senese, indirizzato alle autorità alleate il 6 Luglio 1944, tre giorni dopo la liberazione di Siena, Bracci descriveva una «popolazione rurale mite, gentile e ospitale, molto attaccata alla proprietà e soprattutto al bestiame ${ }^{117}$. II profilo antropologico dell'attaccamento' del contadino alla terra, nel 'mito' della mezzadria toscana, innervava i Discorsi nei paesi della provincia dell'azionista, che sottolineava di parlare in pubblico «dopo trentaquattro anni di silenzio» ${ }^{118}$. Spiegava che «i nostri progetti di riforma agraria» poggiavano sul «metodo democratico», nel rifiuto della «dittatura di classe», dopo quella di «un uomo, nell'Italia imperiale di cartapesta» ${ }^{119}$. Bracci indicava il tema del "diritto del lavoro», poi perno della Costituzione, «misura del nostro valore sociale», nelle "forme più diverse, cooperative o consorzi o piccola proprietà socialmente organizzata» ${ }^{120}$. La prospettiva storica pareva insegnare che $\mathrm{i}$ «primi grandi agri-

\footnotetext{
115 Bandini, 1960, pp. 249 ss.

116 Serpieri, 1947, pp. 101 ss.

117 Bracci, 2020, p. 139.

${ }^{118}$ Bracci, 2020, p. 193. Sullo «stile espressivo semplice e diretto, ricco di esemplificazioni e similitudini, di dolorose immagini di guerra, di racconti di episodi di vita vissuta, di proverbi o battute, così come di richiami ai caduti, ai simboli religiosi e al Vangelo», fino a «utilizzare alcuni slogans della retorica fascista rovesciandone l'esito, per dimostrare il fallimento del regime» Moscadelli, 2020, pp. 35 ss.

${ }^{119}$ Bracci, 2020, p. 210.

${ }^{120}$ Ivi, p. 201.
} 
coltori», in assenza dello Stato, avevano migliorato "le condizioni della terra», premessa alla «proprietà che esiste tutt'ora»,

opera utile a tutti, perchè aumentò talmente la proprietà che ora nella nostra provincia vive una popolazione tre volte più numerosa che centocinquanta anni or sono.

In quel dopoguerra per Bracci era «lo Stato» a dover «raccogliere e distribuire lui la gran parte della ricchezza», nella critica di quei «figli dei figli dei primi grandi agricoltori, addormentati, che, salvo le eccezioni, poco o nulla fanno». Al tempo stesso il giurista senese definiva lo slogan "la terra ai contadini» "un modo di dire», nella presa di distanza dalla predicazione di chi intendeva

mandar via il proprietario di un podere per metterne un altro, sia pure contadino, che possa fare il comodo proprio e magari affittare o rivendere la terra, o farla lavorare dai braccianti a poco prezzo e starsene in paese a giocare a carte e prendersi i prodotti e non pagare le tasse.

Bracci raccomandava gradualismo,

attuare le riforme a settori, progressivamente, secondo le possibilità storiche e politiche: così per esempio affronteremo prima la riforma agraria nel latifondo che nella mezzadria.

Nella consapevolezza di un'agricoltura della Lombardia diversa da quella della Toscana e della Sicilia, il giurista senese proponeva che l'azione riformatrice inziasse dal Meridione ${ }^{121}$. Rivendicando per l'azionismo la «storicità», il «non credere ai miracoli», il dover coinvolgere nella riforma «i nostri contadini dalla mentalità individualista», Bracci argomentava che dovevano rimanere di «proprietà privata tutti i beni che non servono alla grande proprietà agraria [...] questa è davvero questione di libertà». Spiegava poi il senso dei "grandi mezzi di produzione, la terra agraria e l'industria, progressivamente socializzati»,

il che non vuol dire affatto che vogliamo trasferirli in proprietà dei contadini e degli operai, che finirebbero col divenire proprietari come e peggiori di quelli attuali.

In nome del "liberalsocialismo»" 122 l'azionista tematizzava una proprietà 'dinamica', in capo a chi «effettivamente» si avvaleva del bene "per il proprio lavoro [...] affinchè il frutto vada soltanto a compenso di quelli che lo prestano e della collettività, cioè dello Stato»; evocava il "punto di arrivo» di un lungo processo, «occorreranno decenni per vedere a buon punto la costruzione del nuovo edificio sociale» ${ }^{123}$.

L'Opuscolo per i contadini si rivolgeva al "caro mezzadro» - invitato a «rileg-

\footnotetext{
${ }^{121}$ Ivi, pp. 216-220.

122 Ivi, p. 230.

${ }^{123}$ Ivi, p. 227.
} 
gere tra vent'anni questo libretto" - che più di tutti aveva pagato il prezzo del fascismo e della guerra, e che mai aveva dismesso la "voglia di lavorare». Bracci intendeva divulgare nelle campagne i capisaldi del programma del PdA, «socialista per chi sfrutta», «liberale nel metodo». "Con la forza non è possibile fare pure l'aceto» - scriveva il giurista - nella condanna della violenza, all'origine del "fascismo, che può essere di qualunque colore»" ${ }^{124}$, identificato anche dal Discorso I fattori storici con la negazione della libertà «sub specie aeternitatis [...] si chiami fascismo, comunismo o con altri novissimi nomi» ${ }^{125}$. L'azionista ripeteva che «la terra ai contadini non significa nulla»; al "caro mezzadro», cui riconosceva il «lavorare tanto e senza orario», Bracci ricordava che il suo lavoro era fonte di sostentamento anche per la famiglia, di contro a operai ed impiegati di città, alle prese con la borsa nera; gli raccomandava pertanto di

modificare meno possibile le tue abitudini [...] metà dei prodotti come è tuo costume da secoli salvo modificazioni con il patto colonico.

L'azionista spiegava la necessità che, fatti salvi i diritti dei "pochi padroni che fanno qualche cosa», "mosche bianche, veramente agricoltori», lo Stato, "cioè la Comunità», divenisse "padrone di tutte le aziende che abbiano importanza per la comune produzione nazionale». Quanto al profilo anche politico dell'espropriazione, ai tempi delle sanzioni contro il fascismo Bracci prevedeva un esproprio senza indennità per i fascisti che si fossero macchiati di fatti di sangue; per gli altri che avevano servito il regime - «e sono tanti» - riconosceva una indennità, sia pure inferiore al valore delle terre; aggiungeva che negli altri casi il prezzo sarebbe corrisposto al valore. Alla domanda del mezzadro sul come «farsi sentire dallo Stato", "nuovo padrone che manco si vede», Bracci rispondeva che lo Stato avrebbe tenuto per sè poche fattorie, una per Comune; le altre le avrebbe date in concessione, ai contadini riuniti in Consorzi o ai precedenti proprietari, se fossero stati in grado di lavorarvi. Indicava un contratto tra Stato e agricoltore, «senza seccatura di tasse», per cui il concessionario pagava un affitto e uno stipendio a seconda delle sue capacità; aggiungeva che "se è laborioso guadagna di più». Bracci intendeva rassicurare i mezzadri, garantiti dal patto colonico e dalle leggi, difesi dalle organizzazioni; sottolineava che il sistema delle concessioni comportava il conferimento di una somma annua allo Stato e la facoltà per i contadini di tenere come anticipo metà dei prodotti e di dividere quel che avanzava della buona produzione. "Su tutti» - concludeva il giurista - «vigilerà lo Stato»"

In una Conversazione alla radio Bracci parlava del diritto di proprietà fondiaria, ricompreso nel "conflitto» tra quelle che sembravano ricette veteroliberali e collettivizzazione; al proposito irrideva alle «bandiere rosse», paragonate agli aleatori «alberi della libertà in Toscana al tempo napoleonico». L'azionista osservava

\footnotetext{
124 Bracci, 1981o, p. 97.

125 Bracci, 1981b, p. 30.

${ }^{126}$ Bracci, 1981 , p. 107.
} 
che il "contenuto privatistico» delle "aziende agrarie» andava riempiendosi di "contenuti sociali»; citava il "signore di Tocqueville» e prevedeva che «si riderà fra un paio di secoli alla libera proprietà delle grandi aziende agrarie». Le reazioni di un «libello senese», definito da Bracci espressione di una «classe di proprietari agrari, che considera la proprietà e ne usa alla maniera di due secoli orsono", spingeva il giurista senese a puntualizzare il senso del legame tra «libertà e proprietà», con

modeste considerazioni neppure originali, sulla funzione sociale della proprietà e sul suo progressivo trasformarsi da diritto soggettivo a diritto condizionato, che si leggono e che si insegnano anche nei corsi universitari [...] che da un secolo va attuandosi negli ordinamenti giuridici di tutto il mondo ${ }^{127}$.

L'ideario era ripreso in un articolo per II Ponte, dopo che Calamandrei aveva chiesto insistentemente a Bracci un intervento su un «argomento politico o culturale vivo»"128; I'antico allievo sceglieva «il problema giuridico della terra». Nel clima di speranze aperto dal governo Parri, Bracci esordiva con il definire la «riforma agraria quale problema di giustizia»; premetteva, da "non marxista», che in un "paese essenzialmente agrario» il "godimento dei frutti del lavoro agricolo» doveva spettare "esclusivamente a coloro che si avvalgono di questo mezzo di produzione», a seconda del «merito sociale del proprio lavoro». La "superiore giustizia sociale» pareva praticabile entro un "armonico processo storico»; quanto alla "proprietà privata della terra, quale è oggi nella realtà giuridica», Bracci osservava la distanza dalla logica della codificazione civile sul «diritto di godere e disporre della cosa nel modo più assoluto», che andava bene per «una penna stilografica», non per "la terra», "volto della patria», disegnato dal «lavoro degli uomini», con «limiti e obblighi stabiliti dall'ordinamento giuridico». La "produzione agricola» era definita di «interesse pubblico»; da qui la necessità di una «progressiva assunzione da parte dello Stato e di enti pubblici» ed i «doveri positivi nella sfera della proprietà privata», identificata in un «diritto condizionato o affievolito".

L'amministrativista sosteneva che il regime amministrativo della «demanializzazione», «in termini tecnici concessione», doveva prevedere una «soluzione rigidamente legalitaria», non l'esproprio 'rivoluzionario', ma una forma intermedia, con indennità, configurando «il proprietario oggi trasformato in concessionario», senza mettere in discussione «iniziative individuali e spinta del tornaconto personale». Delineava un «sistema tributario» poggiante su canoni rivedibili, in un sistema di organizzazione a base regionale, con Magistrati della terra, incaricati di fissare le tariffe. Dalla presa d'atto dei «non molti proprietari intelligenti e onesti», scaturiva la proposta di una «classe di concessionari privati come unica categoria dei soggetti della produzione agricola». Bracci intendeva collocare

\footnotetext{
${ }^{127}$ Bracci, 1981p, pp. 112-113.

${ }^{128}$ Moscadelli, 2019, p. 379.
} 
la riforma «nella tradizione e costumi italiani», argomentando che il «successo della Rivoluzione russa in campo agrario» poggiava sul "mir, comune forma di proprietà che vive nei secoli della coscienza dei contadini». In Italia distingueva tra coltivatori diretti, piccoli proprietari - un esempio la «mezzadria, nella pura forma toscana» - i salariati nel Mezzogiorno. Riponeva fiducia nella «energia privata, disciplinata anche dai patti colonici», nella «iniziativa individuale strutturata a vantaggio sociale».

Quanto ai «soggetti della concessione», Bracci argomentava che in un primo tempo lo Stato dovesse gestire le aziende nei territori da bonificare e nel latifondo; poi il Comune, ente autarchico, avrebbe assunto la funzione sociale di gestione della terra con aziende agrarie municipalizzate; la fissazione di un canone di lavoro pareva la risposta ai problemi della finanza comunale. II giurista senese sosteneva che la «natura pubblica della produzione agraria» consigliava il ricorso al Consorzio, soggetto pubblico, in grado di «fissare il lavoratore sulla sua terra», istanza sottratta all'immagine della «servitù della gleba». I Consorzi, intesi a legare "le masse lavoratrici all'agricoltura», erano preferiti alle "romantiche ed egoiste cooperative», "società di diritto privato». Per Bracci la «progressiva socializzazione della terra italiana» passava dunque per i Consorzi concessionari, estesi a zone connotate dal lavoro salariale, e per i «privati concessionari» nella realtà mezzadrile, una scelta che pareva coerente sia per una «economia capitalistica che in un tipo di economia socialista». II giurista senese prospettava un modello di concessionario direttore di azienda a servizio delle Comunità, in una necessaria 'moralizzazione' dei soggetti, che investiva anche le «organizzazioni sindacali», vocate a sostenere l'attività di controllo dell'amministrazione «nel rispetto delle leggi».

Quanto alla "piccola proprietà del coltivatore diretto», cara a molti, Bracci scriveva di «piaga sociale», fomite dello sviluppo di uno «spirito grettamente conservatore», "anche se oggi gode di tanti idilliaci favori». Il giurista senese era consapevole che la sua proposta innovativa era rivolta ad un «paese come l'Italia, dove ad ognuno la felicità appare nel miraggio di una signoria individuale della terra». Profilava invece una nuova antropologia del «responsabile del governo agrario e padrone della propria sorte economica», tratto individuante degli «uomini degni all'agricoltura». Per le aziende agricole, con esclusione della minima proprietà, il giurista senese non proponeva le «estreme soluzioni rivoluzionarie, quali la demanializzazione senza indennità», ma l'«espropriazione con corresponsione di indennità, per esempio mediante titoli di Stato, redimibili, a basso saggio di interesse». Una volta trasferita la proprietà della terra allo Stato, Bracci indicava la «gestione dell'attività agricola per titolo di concessione», senza «turbamento rivoluzionario nel costume italiano», piuttosto ordinando «in un istituto giuridico adeguato un fenomeno che ora vive stentato e costretto in una forma giuridica anacronistica». Esso, "attuato gradatamente», pareva funzionale ad un tipo di economia socialista, capitalista, mista, tutte bisognose di «spirito del lavoro», di 
"grande energia sociale», "fiducia quasi religiosa nella solidarietà umana». Per Bracci i «fini pubblici della produzione agraria» e le «esigenze della giustizia sociale» imponevano una precisa funzione «socialmente utile» della proprietà,

non sostituire i titoli privati della proprietà con altri proprietari privati e nemmeno dividere la terra, come il pane evangelico, in tanti orti claustrali, nè giova credere che ciò sia socialmente utile [...] abbandonare l'istituto della proprietà privata per lo sfruttamento della terra e di attuare i fini pubblici della produzione agraria e le esigenze della giustizia sociale con le forme giuridiche adeguate e che sono forme di diritto pubblico ${ }^{129}$.

Nelle carte dell'archivio personale - in parte riversate nelle pagine edite - la «proprietà della terra» era al centro di numerosi appunti, anche sul proponimento di esaminare «monografie» in vista di un ampio lavoro, di cui «il piano per la socializzazione della terra italiana» avrebbe costituito la terza parte. Pur nel carattere 'rapsodico', le riflessioni di Bracci mettevano a fuoco il prisma di problemi della "proprietà della terra in Italia», che il giurista senese non isolava nel dato formale, coniugando storia, "condizioni economiche», "pensiero economico, filosofico, religioso», "istituti giuridici», e, per "l'Italia odierna», "disciplina giuridica». Un 'Indice' de La proprietà della terra in Italia prevedeva un'Introduzione, I' «Italia antica», nel "periodo giustinianeo» - sei carte sull' «agricoltura etrusca» e "storia romana» - I' «Italia medievale», "nei secoli XVII e XVIII», "nel secolo $X I X »$, «nell'Italia odierna». Una 'parte' II indicava "gli istituti della tradizione giuridica italiana per la socializzazione della terra», con un elenco, «1. Le aziende statali, 2. I Consorzi, 3. La mezzadria, 4. La concessione»; una 'parte' III prevedeva, con doppia sottolineatura, La socializzazione della terra italiana.

Nell'Introduzione si annotava

la nozione di giustizia; eguaglianza e responsabilità. A ciascuno secondo i suoi meriti. La giustizia come schema astratto e la sua mediazione per la norma e la coscienza. E' per l'operare della giustizia che si ridesta l'imperativo etico nell'esperienza giuridica. II contenuto concreto della giustizia è storico. La norma giuridica e le altre norme. La continuità della vita giuridica e il problema della norma nuova. Giustizia e legalità. La legittimità del momento rivoluzionario.

Altre carte sulla giustizia, tratte «Da Croce: Il carattere della filosofia moderna», si aprivano con l'affermazione 'programmatica' del lavoro culturale del giurista Bracci, «il pensatore deve soffrire il suo problema e vivere il suo pensiero altrimenti è un retore». Di rilievo anche la distinzione tra «liberalismo morale ed economico», con il primo che poteva "accettare anche un ordinamento comunistico della proprietà», con la sottolineatura di un particolare "errore»,

distinguere tra libertà giuridica o 'formale' e libertà di fatto o 'reale': la seconda sarebbe ancora da conquistare. La prima è la libertà, la seconda è un ordinamento

${ }^{129}$ Bracci, 1945, p. 190. 
economico, ma la libertà non si identifica con alcun ordinamento economico.

Del «De Ruggiero» - citando dalla III edizione della Storia del liberalismo in Europa - Bracci appuntava alcune pagine, a proposito di «limiti della proprietà nell'interesse familiare privato, (fedecommesso)»; di «limiti dello Stato rispetto ai diritti individuali (aspetto negativo) e i diritti individuali che hanno significato soltanto per mezzo dello Stato (aspetto positivo)». II «riconoscimento dei diritti individuali e dei frutti individuali della libertà» appariva come l'architrave del «liberalismo»; la "ridistribuzione violenta di valori e di beni sociali ed espropriazione dei beni e diritti individuali per intestarne la collettività» era identificata con il «socialismo». Bracci appuntava poi il suo 'progetto giuridico',

riconoscimento dei diritti individuali, ma condizionato in concreto all'interesse collettivo e la loro funzionalità pubblica attraverso l'attribuzione allo Stato dei beni e valori d'interesse collettivo. II diritto individuale ha un nucleo di interesse direttamente irrilevante: altrimenti deve essere costruito come l'esercizio di una pubblica funzione.

Alcuni appunti su Proprietà riportavano De Ruggiero,

storicità, che si impone anche nella scelta degli istituti giuridici quando le nuove esigenze di giustizia sono generali [...] evoluzione della nozione di proprietà in rapporto alle esigenze storiche di giustizia dall'origine ai giorni nostri [...] istituti storicamente adeguati per il nostro popolo.

Bracci appuntava poi - citando Emile de Laveleye, De la propriété ed des formes primitives del 1874 - che «l'uso collettivo della terra da parte di un gruppo sociale è uno stadio rudimentale della civiltà»; che la "proprietà» era "conseguenza del passaggio dallo stadio nomade allo stato fisso», che la "terra d'uso pubblico» non era suscettibile di esclusivo sfruttamento individuale», che «la dinamica degli egoismi portò dalla proprietà collettiva alla proprietà individuale» ${ }^{130}$.

Territorio per l'uso agrario si presentava come una sorta di 'proposta normativa' non conclusa,

occorrerebbe conoscere il valore della proprietà terriera italiana, il reddito domenicale, il gettito delle imposte fondiarie, il numero delle aziende agrarie distinte per categorie secondo l'estensione, il numero dei proprietari, affittuari, mezzadri, braccianti, tecnici agrari.

Bracci indicava il «territorio di uso agrario» come uno delle "categorie» in base alla «destinazione, la produzione agricola»,

il territorio nazionale, compreso il sottosuolo, fa parte del patrimonio indisponibile dello Stato. Esso deve essere utilizzato socialmente a cura dello Stato, degli Enti pubblici che hanno tale funzione e da coloro che ne abbiano avuto la commissione.

${ }^{130}$ ASS, Archivio personale Mario Bracci 49, ins. 21, La proprietà della terra. 
Per i profili organizzativi il giurista senese annotava che il «potere esecutivo, sentito il parere del Consiglio superiore dell'economia, dovesse determinare decennalmente sulla base regionale il piano colturale nazionale». Come "soggetti della produzione agraria» indicava "le aziende agrarie dello Stato - cui riconoscere "personalità giuridica di diritto pubblico», con autonomia contabile ed amministrativa - i Consorzi dei produttori agrari, i privati concessionari. Pensava ad aziende agrarie "modello», rette da un Consiglio di amministrazione, composto dall'ispettore agrario provinciale, il direttore della sede provinciale della Banca d'Italia, tre esperti nominati dal Ministero dell'Agricoltura. I Consorzi dei produttori erano indicati come enti pubblici, con "personalità giuridica», costituiti con decreto governativo, facoltativi o obbligatori, composti da coltivatori diretti, tecnici agrari, proprietari che abbiano «capacità agrarie». Questi ultimi potevano investirvi i titoli ricevuti come indennità di espropriazione e convertirli in obbligazioni del Consorzio, con lo Stato chiamato a rimborsare i titoli. I privati concessionari, individui o società a responsabilità limitata, ricevevano la terra in concessione ed erano limitati alle zone a mezzadria. Bracci appuntava di evitare sia le estensioni troppo piccole, che le troppo grandi; delineava una «amministrazione molto semplice», demandata all'Assemblea dei consorziati, presieduta da un direttore di nomina assembleare, con approvazione del Magistrato della terra, organo consultivo e di controllo, regionale e provinciale, che avrebbe dovuto svolgere le funzioni del Consiglio superiore dell'agricoltura. Per i privati concessionari, organizzati nelle unioni provinciali, Bracci proponeva l'assorbimento delle funzioni degli operativi Consorzi agrari, con funzioni di assistenza agraria e tutela sindacale. Bracci elencava poi i lavoratori agricoli, braccianti, mezzadri dipendenti da consorzi e privati concessionari, «organizzati sindacalmente sul tipo odierno»; un appunto citava De Ruggiero, a proposito della «associazione stato in embrione, non può sussistere nello Stato".

Le Norme transitorie erano lo 'specchio' delle idee di Bracci sulla «giustizia»,

il territorio agrario passa allo Stato per confisca o per espropriazione. La determinazione dell'idennità di espropriazione dovrà avvenire con criteri di giustizia retributiva nel senso che i portatori della proprietà terriera devono realizzare una ricchezza mobiliare pressappoco nelle stesse proporzioni dei portatori di titoli di stato e dei titoli fondiari. E' possibile applicare criteri di discriminazione politica con effetti intermedi tra la confisca e l'espropriazione. L'indennità viene corrisposta in titoli di stato a basso saggio di interesse. II piano finanziario deve essere organizzato in modo che le entrate dei canoni di concessione (che devono assorbire gran parte del reddito domenicale) servano per il servizio degli interessi e per l'ammortamento dei titoli detratta la quota che in base ai tributi fondiari attuali alimentano le entrate generali dello Stato ${ }^{131}$.

${ }^{131}$ ASS, Archivio Mario Bracci, 49, ins. Territorio per l'uso agrario. 
Un dattiloscritto riproduceva «queste idee, fissate schematicamente in articoli, al solo scopo di fissare per memoria alcuni punti per l'esame di un problema concreto"; il territorio agrario era definito parte del nazionale, destinato alla produzione agricola o forestale. Tra le novità, rispetto alle carte manoscritte, risaltava l'idea che l'esecutivo, "sentito il parere del Consiglio superiore dell'economia pianizzata», determinasse "decennalmente sulla base regionale il piano culturale nazionale». Bracci elencava poi i consueti «soggetti della produzione», «le aziende agrarie dello Stato, i consorzi dei produttori agrari, i privati concessionari». Definiva nel dettaglio «organizzazione e controlli»; le carte dedicate al Magistrato provinciale si chiudevano con «(incompleto») 132 .

In un dattiloscritto per il Nuovo corriere nell'Aprile 1948 I'«agitazione dei contadini» pareva necessaria alla «salvezza d'Italia», col dover durare fino al «successo della riforma agraria». Bracci accusava $\mathrm{i}$ «nostri agricoltori» di non volere «aiuti finanziarie, leggi agrarie, consigli tecnici», ma solo di "contadini disciplinati», nell'illusione di "vincere le nuove battaglie del grano», innalzando "bandierine, che ieri erano l'orgoglioso gagliardetto, ora l'interesse dell'Italia». II giurista asseriva che la "salvezza dell'Italia» non poggiava su una "questione ideologica, ma di vita», e che nella crisi drammatica, "peggio del 1922», per i "milioni di affamati» non sarebbero bastati «legnate e olio di ricino». Bracci sottolineava la sua proposta,

ciascuno riceva soltanto quella quota di reddito agrario che sia compenso effettivo che egli compie in agricoltura, il resto deve andare alla collettività.

Per Bracci con questo assunto «lo stesso problema teorico della proprietà terriera passa in secondo piano»; su tutto irrompeva il «lavoro», per cui il «compenso o reddito» del proprietario dipendeva dal «lavoro, organizzativo tecnico, direttivo», pazienza per i «fannulloni, i pigri e gli incapaci»; nel dattiloscritto vi era un aggiunta a penna, «contadini o proprietari che siano» ${ }^{133}$.

\section{La proprietà terriera nella Costituzione}

In vista della «riforma costituzionale dello Stato italiano» la Rivista di diritto agrario avviava una "Inchiesta sulla proprietà fondiaria», ponendo una alternativa cruciale - destinata a far discutere sul piano generale - tra il «contenere principi della riforma agraria» e l'«enunciazione di mero carattere etico-politico, affidata alla interpretazione del legislatore», "Costituzione in senso giuridico, che indichi gli istituti e le figure che contengono l'attuazione dei principi politici oppure no».

Mortati motivava la proposta di «statuizione costituzionale», intesa a coniugare proprietà privata ed interesse sociale per lo sviluppo dell'agricoltura, in considerazione dell' «Italia paese prevalentemente agricolo» e del «periodo di vaste

\footnotetext{
${ }^{132}$ ASS, Archivio Mario Bracci, 49, ins. 4.

${ }^{133}$ ASS, Archivio Mario Bracci, 49, ins. 2.
} 
trasformazioni sociali, come il presente ${ }^{134}$. Anche Felice Battaglia conveniva sulla «riconnessione tra proprietà e lavoro», iscritta nel superamento del "mero piano individualistico albertino» per un "più ampio piano economico sociale». Ricordava l'eperienza di Weimar e metteva in guardia dal "pericolo», iscritto in talune Costituzioni, «che si affidano solo al tecnicismo e non al proposito di ben radicati costumi ${ }^{135}$.

II 3 Ottobre 1946 Fanfani consigliava alla terza Commissione, incaricata dall'Assemblea costituente di esaminare i problemi economico-sociali, "un articolo che parli espressamente della terra», scelta che riconosceva inopportuna dal "punto di vista strettamente giuridico», ma decisiva su quello "psicologico e politico», in risposta all'accesa conflittualità nelle campagne ed all'occupazione delle terre. All'argomento per cui la Costituzione già subordinava la tutela della libertà privata agli interessi generale, con la previsione espressa dell'espropriazione, Fanfani rispondeva con un argomento 'costituzionale',

non si tratta di fare della demagogia ma bisogna tener presente che la Costituzione non va soltanto in mano a dei giuristi ma alle più svariate categorie di cittadini. Una buona metà del popolo italiano cercherà nella Costituzione non un qualche inciso sibillino che faccia pensare ad una trasformazione agraria, ma almeno un articolo che parli chiaramente delle terre.

Erano d'accordo i comunisti; Teresa Noce definiva il «problema agrario uno dei più sentiti»; Pesenti, relatore, proponeva la nazionalizzazione di ogni impresa agricola, mentre il democristiano Dominedò restingeva l'ipotesi ad una 'extrema ratio'. Un altro tema riguardava le formule in grado di vincolare il legislatore futuro ad attenersi al dettato costituzionale; il presidente Ghidini tematizzava la ricerca di «statuizioni», in grado di "aprire la strada alla riforma agraria»; Canevari, promotore della cooperazione, affermava che «è indispensabile che la Carta costituzionale contenga direttive e impegni per la riforma agraria attesa da tutto il paese ${ }^{136}$.

Il latifondo risaltava come la questione più urgente e divisiva; Giuseppe Di Vittorio ne chiedeva l'eliminazione,

perché in tal modo si elimina l'arretratezza della nostra agricoltura, si elimina la miseria dei nostri braccianti e dei nostri piccoli contadini: e non soltanto nel Mezzogiorno, ma anche in altre regioni d'Italia [...] con il profondo rinnovamento democratico dell'Italia [...] nelle masse popolari del nostro Paese è penetrata profondamente la coscienza che i diritti esclusivamente politici non bastano più; è penetrata la coscienza della necessità della realizzazione delle riforme sociali di struttura della economia, che sono la sola garanzia effettiva e positiva del godimento dei buoni diritti che la Carta costituzionale riconoscerà ai lavoratori italiani.

\footnotetext{
${ }^{134}$ Mortati, 1947 pp. 3-13. Sul costituzionalista cfr. Fioravanti, 2013, pp. 1386-1389.

${ }^{135}$ Battaglia, 1947, pp. 14 ss.

${ }^{136}$ La Costituzione della Repubblica nei lavori preparatori dell'Assemblea costituente, VIII, 1971, p. 2215 ss.
} 
La formula della «trasformazione» del latifondo, proposta da Luigi Einaudi, convinceva l'Assemblea, con l'argomento di evitare l'astrattezza di scelte «dottrinarie», avulse dalla conoscenza dell'effettiva consistenza dei latifondi nelle diverse 'Italie rurali'; Einaudi definiva l'abolizione «assurda e nociva» e proponeva la formula della "trasformazione a seconda delle esigenze, delle culture, delle diverse zone agrarie» ${ }^{137}$. Fanfani poneva l'esigenza di rimandare alla «legge» la «ripartizione tra i lavoratori delle terre non sufficientemente sfruttate»; sollevava il problema della mancanza di istituzioni, come le cooperative e i consorzi, a sussidio della piccola e media proprietà; auspicava l'incoraggiamento da parte dello Stato nella risoluzione e revisione dei patti agrari; riprendeva l'orizzonte 'serpieriano' di una bonifica che non riguardasse solo il prosciugamento delle paludi, ma la dotazione di strade, case coloniche, e soprattutto un radicale rinnovamento della cultura agraria, pena un'opera vana. Non era accolta una formula generale,

lo Stato, per la migliore valorizzazione della terra, nell'interesse sociale e dei coltivatori, promuove le trasformazioni fondiarie necessarie, favorisce le istituzioni ausiliarie della media e piccola proprietà, dispone l'aggiornamento dei patti agrari, completa la bonifica, agevola la diffusione dell' istruzione agraria.

Paolo Emilio Taviani, relatore, proponeva di recepire un «principio generale, pur non essendovi la possibilità di arrivare subito a porlo in atto»,

la Repubblica persegue la razionale valorizzazione del territorio nazionale nell'interesse di tutto il popolo e allo scopo di promuovere l'elevazione materiale e morale dei lavoratori [...] con precise disposizioni di legge si potrà imporre obblighi e vincoli alla proprietà terriera [...] la possibilità per il contadino di accedere alla proprietà della terra è un principio ormai adottato da tutti i partiti di massa ${ }^{138}$.

La previsione dell'ostacolare le grandi proprietà terriere private restava fuori del testo definitivo dell'art. 44,

al fine di conseguire il razionale sfruttamento del suolo e di stabilire equi rapporti sociali, la legge impone obblighi e vincoli alla proprietà terriera privata, fissa i limiti alla sua estensione secondo le regioni e le zone agrarie, promuove e impone la bonifica delle terre, la trasformazione del latifondo e la ricostruzione delle unità produttive; aiuta la piccola e la media proprietà. La legge dispone provvedimenti a favore delle zone montane.

'A caldo' Bolla celebrava il «nuovo diritto fondiario, manifestamente ostile alla proprietà individuale», perché poggiante sul "principio della "socializzazione" della terra», inteso a "trasformare la proprietà individuale in proprietà sociale». "ll tempo della proprietà speculazione, si dice, è finito», asseriva il direttore della Rivista di diritto agrario,

\footnotetext{
137 Ivi, p. 1696 ss.

${ }^{138}$ Ivi, p. 2142; Taviani, 2002, pp. 111 ss.
} 
la proprietà, lungi dall'essere un diritto sacro e inviolabile, assume il carattere di un diritto continuamente cangiante, che deve modellarsi sui bisogni sociali. E se giunge un momento in cui la proprietà individuale non apparisce più corrispondente ai bisogni sociali il legislatore ha facoltà, non solo di portare a essa tutte le restrizioni che egli ritenga del caso, ma di scegliere altra forma di appropriazione di queste ricchezze [...] l'art. 44 non definisce un diritto ma la destinazione di un bene produttivo a uno scopo, che esige una sua tipica e specifica organizzazione ritenuta fondamentale alle rinnovate esigenze della vita in comune nel presente momento storico ${ }^{139}$.

Dal canto suo il civilista Filippo Vassalli definiva l'art. 44 «una specie di ricettario o prontuario per la risoluzione del problema agrario», "senza novità di idee» ${ }^{140}$.

\section{I compiti per il «legislatore futuro»: la proprietà fondiaria nella riforma agraria}

È stato osservato che, a parte quella dei Soviet, la Costituzione italiana era l'unica a prevedere un articolo sulla proprietà privata sulla terra, non in quanto tale, ma perché destinata o destinabile alla produzione; da qui i limiti imposti al titolare per la destinazione produttiva del bene in un particolare tornante d'epoca,

l'urgenza della questione agraria imponeva di sciogliere sul terreno stesso della disciplina costituzionale quei nodi che, per il resto della disciplina proprietaria, venivano affidati al legislatore futuro ${ }^{141}$.

Il quadro politico era destinato a segnare il percorso riformatore; nel 1948 Rossi Doria interveniva ai Georgofili a proposito di un «mito», nato nel 1945, quando tutti avevano creduto in una "radicale riforma agraria, che investisse tutta le grande e media proprietà», con una "visione ideale, programmatica, teorica». Quel "mito» pareva alimentato dal fatto che l'Italia era "uno dei pochissimi paesi al mondo nei quali la proprietà della terra è in massima parte di chi non la lavora». D’altro canto Rossi Doria osservava che, «dopo il 18 Aprile», era impossibile "una riforma radicale e profonda»; proponeva pertanto una "diversa politica», poggiante sulla riforma dei contratti agrari, l'intensificazione della bonifica, la trasformazione del latifondo in proprietà contadine «in zone adatte». Ripeteva di scongiurare «norme uniformi» per un'Italia i cui «problemi» dovevano esser affrontati «in modo diverso»; auspicava che nella «politica» per l'agricoltura non si «immischiassero i giuristi», ancorati ad una prospettiva astrattamente ugualitaria, con l'esempio della pretesa di togliere 10 mila ettari al principe Corsini, se altrettanti erano stati tolti al Principe Torlonia, senza che l'operazione fosse

\footnotetext{
${ }^{139}$ Bolla, 1949, pp. 2 ss.

140 Passaniti, 2017, p. 148.

${ }^{141}$ Rodotà, 1982, p. 213; cfr. anche Giuffrida, 2019, pp. 89 ss.; Atripaldi, 2020, pp. 13 ss.
} 
richiesta dalla "pubblica utilità» ${ }^{142}$.

Nel Novembre 1948 Segni presentava alla Camera il disegno di legge Disposizioni sui contratti agrari di mezzadria, affitto, colonia parziaria e compartecipazione, mai approvato. In particolare i giuristi criticavano il progetto dalla prospettiva della "dittatura del legislatore», in un settore particolare, quello dei contratti, che parevano nati dai fatti, irriducibili ad essere definiti in modo uniforme per legge. Carnelutti osservava che, «in Italia», coincidevano "legge e democrazia», anzichè "diritti e democrazia» ${ }^{143}$. Azzariti contestava l'alterazione della nozione di contratto, con i rapporti personali trasformati in diritti reali; polemicamente chiedeva di «riportare le leggi al diritto» ${ }^{144}$. Bassanelli osservava il «vasto movimento del mondo del lavoro, che reclama certezza e stabilità per l'impiego delle energie lavorative», e gli «interessi della Comunità»; riteneva il «quadro non semplice», nel momento in cui la «moderna agricoltura» pretendeva prestazioni d'impresa, «al di là della mera conservazione». Criticava peraltro l'«irruzione della legge» ed il "progressivo indebolimento dell'autonomia privata», letti nel "progetto Segni sulla riforma dei contratti agrari» ${ }^{145}$. Citando Jacini, Bassanelli indicava "varietà e forme nuove» dei lavori, per cui pareva «incauto introdurre una riforma con la legge», nella sottolineatura del nesso tra "contratti agrari e vita», dell' "accordo collettivo» come "esperienza consapevole», "vincolato alle condizioni delle diverse agricolture regionali»; dichiarava «non siamo feticisti, ma la consuetudine ha funzione insopprimibile per la varietà dell'agricoltura italiana» ${ }^{146}$. In un Corso di lezioni Emilio Betti si pronunziava contro le proposte di uniformare per legge i contratti agrari, osservando un 'demagogico' vantaggio per mezzadri, affittuari, coloni, e un disinteresse per la posizione dei concedenti. II giurista camerte si opponeva alla 'pubblicizzazione' e poneva con decisione i contratti agrari nella disciplina agraristica, "branca del diritto civile» ${ }^{147}$. Su /l Messaggero Serpieri affermava che i "rapporti equi tra capitale e lavoro» dovevano essere rimessi al "contratto collettivo, non alla legge», con la sottolineatura che la riforma agraria si componeva di due parti, la proprietà fondiaria e i contratti agrari, che lo Stato doveva promuovere, ma senza che gli artt. 42 e 44 della Costituzione si traducessero in un' «imposta sul reddito» ${ }^{148}$.

Nel cuore delle lotte contadine dell'autunno del 1949, sull'onda dell'emozione per gli eccidi di braccianti a Melissa, Montescaglioso, Torremaggiore, il governo accelerava l'iter della riforma; De Gasperi, contrario ad una legislazione uniforme per il paese, consigliava Segni di concentrarsi sul Mezzogiorno. II 2 dicembre il

\footnotetext{
${ }^{142}$ Rossi Doria, 1958, pp. 47-59.

${ }^{143}$ Carnelutti, 1954, p. 32.

${ }^{144}$ Azzariti, 1954, p. 369.

${ }^{145}$ Bassanelli, 1948, pp. 163 ss.; analogamente Vassalli, 1949, pp. 19 ss.

${ }^{146}$ Bassanelli, 1954, pp. 784 ss.

${ }^{147}$ Betti, 1957, pp. 1, 111 ss, su cui Passaniti, 2017, p. 185.

${ }^{148}$ Serpieri, 1947, pp. 181 ss, 215 ss.
} 
ministro dell'Agricoltura e foreste presentava al Senato il disegno di legge Provvedimenti per la valorizzazione dell'Altopiano della Sila, territorio che presentava una particolare concentrazione della proprietà fondiaria assenteista; da qui la legge Sila (I. 230 del 21 maggio 1950). II 17 marzo 1950 Segni presentava alla Camera Norme per la espropriazione, bonifica, trasformazione ed assegnazione dei terreni ai contadini; indicava come cuore vitale delle norme la «realizzazione della nuova piccola proprietà», dopo che già nei primi mesi del 1948 erano state varate le Provvidenze a favore della piccola proprietà coltivatrice. II ministro spiegava di non voler seguire $\mathrm{i}$ "sistemi vigenti nel ventennio fascista», non "la battaglia del grano», non una "formula assoluta e preconcetta dal punto di vista giuridico sociale», piuttosto una "strada nuova», "una più equa ripartizione della proprietà fondiaria e maggiore occupazione di lavoratori agricoli». Lo «scorporo», cioè l'esproprio, ex art. 44 era indicato come "sacrificio degli interessi dei singoli», "contributo di coloro che più hanno al bene comune». Segni aggiungeva che le "organizzazioni consortili» erano incaricate di attuare, ex articoli 42 e 44, la «realizzazione della nuova piccola proprietà», per cui l' «impresa del lavoratore agricolo» si sarebbe svolta in terreni di proprietà degli stessi lavoratori» ${ }^{149}$.

La legge-stralcio' n. 841 del 21 Ottobre 1950 per le zone particolarmente depresse - finanziata in parte dal piano Marshall, di rilevanza strategica sul piano internazionale - pur nell'ostilità degli ambienti conservatori prevedeva l'esproprio coatto, la distribuzione di terre ai piccoli proprietari imprenditori e la promozione di cooperative. Nel momento in cui la Costituzione sembrava «inattuata» o "congelata», grazie al forte intervento pubblico erano espropriati circa 749.000 ettari di terreno, per il $60 \%$ nel Mezzogiorno e nelle isole. I poderi assegnati ne misuravano in media 6-8; vi era l'insediamento di 121.621 nuclei familiari, con 300.000 unità lavoratrici ${ }^{150}$. Su proposta di Segni la Camera nel novembre 1950 approvava, con il voto favorevole delle Sinistre, una riforma dei contratti agrari, intesa a far sì che la «libera lotta economica» non sacrificasse la parte «più debole». Si disponevano, tra l'altro, la disdetta per giusta causa, l'obbligo di miglioramento per il concedente, il diritto di prelazione sull'acquisto del terreno per l'affittuario, la trasformazione della mezzadria in affitto. La mancata ratifica non era iscritta solo in una svolta politica più 'conservatrice' del governo ${ }^{151}$, quanto nelle resistenze all'uniformazione di pratiche contrattuali diverse, radicate nelle 'Italie agrarie'. Su II mondo Rossi Doria riconosceva a Segni il merito di avere «ancorato a terra il pallone della riforma agraria, che, dalla caduta del fascismo, continuava a vagare libero negli astratti cieli dell'ideologia». II governo pareva «deciso ad

\footnotetext{
${ }^{149}$ Cova, 1993, pp. 94, 319 ss.

${ }^{150}$ Cfr. Bernardi, 2008, pp. 67 ss.; sui provvedimenti, ispirati da un 'paternalismo pubblico' cfr. Rodotà, 2011, pp. 97-98; sui patti agrari, ancorati all'intervento pubblico in economia come esempi di Costituzione attuata cfr. Caretti, 2013, p. 346; Mattone, 2016, pp. 534 ss. ${ }^{151}$ Mattone, 2016, pp. 554 ss.
} 
adempiere all'impegno preso con la Costituzione» ${ }^{152}$, col «ridurre il peso della grande e grandissima proprietà assenteistica», trasformata in agricoltura estensiva, ed «elevare le condizioni di vita delle classi rurali in stato di particolare miseria ed instabilità ${ }^{153}$. La "redistribuzione della proprietà» come attuazione del "concetto vero» della Carta risaltava nel giudizio sulla riforma agraria di Luigi Einaudi,

aver scelto alcune zone nelle quali dar opera alla redistribuzione della proprietà [è] approssimazione al concetto vero, che è quello di impedire che in una zona agraria abbia troppa parte, assorba cioè una quota eccessiva del territorio totale, la grandissima proprietà ${ }^{154}$.

La riforma agraria era al centro degli interventi al Terzo Congresso nazionale di diritto agrario, svoltosi a Palermo nel 1952; Bolla salutava la «nuova Costituzione politica», che "dedica alla terra una specifica dichiarazione». Sottolineava la novità dell'aver attribuito "alla Regione competenza normativa in materia agraria e forestale»; una "nuova fase» pareva aprirsi nel segno del "progesso, solidarietà e quindi pacificazione sociale ${ }^{155}$. In particolare la proprietà terriera pareva connotata dal "carattere sociale», con una netta innovazione rispetto a quella "tradizionale»; per Bolla la crisi dell'istituto derivava dal distacco tra istituzione e funzione, per cui dall'art. 544 del code civil al tentativo di code rural il legislatore aveva cercato di colmare la lacuna. La proprietà fondiaria, «situazione oggettiva e istituzione tipica», risaltava nella 'lunga durata' del «dominium» e della "solidarietà fondiaria», nel segno del superamento dell' «individualismo» della disciplina di un «bene qualificato dallo scopo»"

Intervenendo ad un Convegno dei giuristi cattolici, Segni offriva una 'interpretazione autentica' della riforma, sostenendo che l'Assemblea costituente aveva trovato il problema dell'occupazione e concessione delle terre aperto dai tempi dell' «altro dopoguerra», e che l'art. 44 aveva tracciato precisi «compiti» al «legislatore futuro». Ricordava la proposta di Taviani sulle estese proprietà fondiarie, che dovevano essere «impedite dalla Repubblica», e quella di Fanfani sul «diritto dello Stato di controllare». Segni asseriva che la «funzione sociale» della proprietà era alla base della riforma agraria, poggiante sul "contenuto complesso» dell'articolo 44 , la «tutela della piccola e media proprietà», che non implicava l'«eliminazione della grande proprietà terriera, posizione che politicamente solo i partiti di estrema sinistra possono sostenere». II giurista sardo aggiungeva che il principio degli «equi rapporti sociali e razionale sfruttamento del suolo» oltre che l'art. 44 innervava anche gli artt. 1, 3, 42, attuati dal legislatore con la legge 15 Maggio 1950 per la colonizzazione della Sila e con la legge-stralcio, intesa a

\footnotetext{
152 Rossi Doria, 1956b, p. 76.

${ }^{153}$ Rossi Doria, 1956b, p. 130.

${ }^{154}$ Einaudi, 1956, p. 477.

155 Bolla, 1954a, p. IV.

${ }^{156}$ Bolla, 1954b, pp. 241 ss.
} 
regolare «condizioni diverse dove sono situazioni diverse». Segni sosteneva che le norme erano "costituzionalmente valide», dal momento che non intaccavano il diritto di proprietà, "non degradato ad interesse in alcun punto»; argomentava che lo "scorporo» escludeva l'enfiteusi coatta e si conciliava con "l'istituto della proprietà anche borghese».

In merito alle critiche dell'art. 1 - «il governo, per delegazione concessa con la presente legge [...] provvede con decreti aventi valore di legge ordinaria» - che aveva sollevato "polemiche e controversie», Segni rispondeva citando i Principi di diritto costituzionale di Orlando, per cui la «tripartizione dei poteri» in questo particolare settore era "fallace». II ministro ricordava inoltre che le leggi erano state votate quasi all'unanimità, dal momento che i «dissensi» non riguardavano i "principi», e che l' "applicazione», irriducibile a "regresso» dell'agricoltura, non era ispirata da "volontà di persecuzione», piuttosto da "volontà di miglioramento e giustizia». Indicava infine una novità rilevante; l'istituzione degli Enti di riforma - preposti all'assegnazione ed attuazione della legge - considerata in continuità con le pagine di Calamandrei del 1920, dedicate ai «giudici speciali di equità», e con il «magico e profondo scritto di Capograssi» ${ }^{157}$.

Lo scritto di Giuseppe Capograssi, citato da Segni, faceva riferimento al «linguaggio pittorescamente incolto della Costituzione», a proposito dello "sfruttamento», cui il filosofo del diritto preferiva la formula "unione con la vita della terra». Nel momento in cui pareva attenuato il ciclone delle proteste contadine, ma non l'istanza di interventi legislativi per l'agricoltura del paese, Capograssi guardava al diritto agrario come al terreno d'elezione per lo studio di una "esperienza diretta e concreta nella quale e dalla quale nasce», imposto, "dopo la catastrofe», dallo "stato di necessità», "che muove le cose sociali». Rispetto all' "arido Locke», I'Inchiesta Jacini appariva un documento attento alla concreta situazione del paese, così come le analisi dei Romagnosi e Cattaneo; Capograssi ricordava la "carnalità» dell'intreccio tra "comunità e terra» nelle pagine di Virgilio e Proudhon. La «natura delle cose» pareva rendere impensabile un ordine giuridico uniforme del «lavoro in agricoltura»; quanto alla «strana cosa che è la proprietà individuale della terra», il giurista di Sulmona rispondeva ai problemi del mondo del lavoro con l'accento sull'imprenditorialità rispetto alla astratta titolarità della proprietà, una «sintesi tra umanità e terra [...] non oggetto di sfruttamento ma vita ${ }^{158}$.

Pugliatti interveniva su questo prisma di temi e problemi con un ampio intervento, poi presentato come il suo «lavoro più impegnativo» ${ }^{159}$. Il giurista messinese si riallacciava dunque al Convegno su La concezione fascista della proprietà, osservando che "non vi è una sola proprietà, ma vi sono delle proprietà», «unità concettuale e molteplicità delle situazioni»; argomentava che dal nesso

\footnotetext{
${ }^{157}$ Segni, 1954a, pp. 829 ss; Segni 1954b, pp. 683 ss.

${ }^{158}$ Capograssi, 1952, pp. 246 ss, su cui Cazzetta, 2003, pp. 3 ss.

${ }^{159}$ Pugliatti, 1954c, p. VII.
} 
terra e lavoro emergeva la proprietà produttrice. Pugliatti era consapevole della svolta, impressa dalla Costituzione, irriducibile a norma programmatica; asseriva che, nel silenzio del codice civile, «il testo di legge fondamentale» aveva sancito la "funzione sociale della proprietà» ex articolo 44, delineando la "proprietà funzione». Per Pugliatti la Costituzione esigeva il «principio della massima attuazione», che pareva aver trovato "parziale applicazione» nella legge stralcio del 20 Ottobre 1950 e nella legge regionale siciliana del 27 Novembre 1950 in tema di terre incolte. Pugliatti sottolineava che l'espropriazione non annullava la proprietà, identificata dall' «interesse tutelato»; costituiva "la premessa per una diversa distribuzione», con «dosaggi pubblici e privati». Concludeva che «la proprietà non ha oggi, se mai ha avuto, un significato univoco» ${ }^{160}$.

Francesco Santoro Passarelli discuteva criticamente il «linguaggio pittorescamente incolto" di Capograssi e l'idea della "funzione precettiva immediata» dell'art. 44 di Pugliatti; ribadiva, alla luce degli artt. 42, 44, 47 la «proprietà privata fondamento dell'ordine economico e giuridico». La funzione sociale non pareva posta dalla Costituzione «in odio alla proprietà privata della terra», ma configurata come diritto soggettivo, pena "passare ad altro tipo di economia». Santoro Passarelli spiegava poi la complessità di riformare i contratti agrari con «innovazioni importanti» rispetto al codice civile; da qui le incertezze del Parlamento. Tra i punti discussi segnalava la durata di nove anni per i contratti associativi, nove per l'affitto, la disdetta motivata per giusta causa e indennizzo, la destinazione ai miglioramenti di quote parti del prodotto, il diritto di prelazione del coltivatore diretto dopo due anni dall'inizio del rapporto in caso di alienazione, la quota superiore alla metà nella mezzadria, l'indennità a carico del concedente per disdetta senza giusta causa, intesa come liquidazione piuttosto che "sanzione» ${ }^{161}$.

I giuristi intervenivano da più punti di vista sui diversi nodi della legislazione; Guido Landi discuteva il DI 16 Settembre 1947, che accordava al prefetto, previo parere di una Commissione centrale presso il Ministero del lavoro e previdenza sociale, di assumere manodopera dove era più grave la disoccupazione, con riferimento ai principi personalistici e lavoristici della Costituzione, il «diritto dell'uomo della terra proprietario terriero e soprattutto imprenditore agrario, cioè agricoltore ${ }^{162}$. Silvio Lessona collegava la normativa sulla concessione delle terre incolte ai provvedimenti del primo dopoguerra, 'precedente' della legislazione susseguitasi dal 1944 al 1954, collegandola all'art. 4 della Costituzione, declinato come «potere dovere di lavorare» ${ }^{163}$. Ugo Natoli criticava invece la prassi «sconfortante» dell'attuazione dell'art. 44 , che aveva posto "categoricamente le esigenze della riforma agraria». Il civilista messinese osservava che la funzione degli Enti lasciava a desiderare; che l'assegnatario non diveniva proprietario, se non

\footnotetext{
${ }^{160}$ Pugliatti, 1954c, pp. 46 ss; analogamente Rivalta, 1954, pp. 321 ss.

${ }^{161}$ Santoro Passarelli, 1954, pp. 919 ss.

162 Landi, 1954, pp. 459 ss.

163 Lessona, 1954, p. 852.
} 
dopo aver pagata l'ultima rata di prezzo; che non era stato realizzato l'ordinamento della cooperazione. In particolare Natoli chiedeva al legislatore "garanzie» per gli assegnatari, in quanto «parte debole» ${ }^{164}$.

Nelle Note esegetiche del costituzionalista Esposito all'art. 44 la proprietà fondiaria era collocata tra le esigenze collettive da soddisfare e la garanzia di interessi privati, di cui era architrave l'art. 41. Per il giurista napoletano l'assunto della proprietà del fondo che obbliga non riguardava il se, piuttosto il come coltivare, il modo di sfruttamento, se assumere, mantenere o rinunziare alla «veste di proprietario della terra con tutti gli obblighi corrispettivi». Esposito considerava che la Costituzione indicava il «fondamento immutabile della nostra economia agraria» nella "proprietà terriera privata, non in quella collettiva o pubblica»; escludeva la possibilità per il legislatore di «conculcare la libertà di svolgimento dell'iniziativa economica privata», anche in un'eventuale "possibilità di enti nazionalizzatori dei beni», pena vanificare il principio costituzionale, reso in una "solenne dichiarazione di libertà»" 165 . Mortati sgombrava il campo da qualsiasi ipotesi di nazionalizzazione dell'agricoltura, con il leggere il cuore vitale della riforma agraria nell' 'ampliamento del piccolo e medio possesso". Anche il costituzionalista calabrese sottolineava la prevalenza della proprietà privata su quella pubblica, entro un sistema di economia mista, la prima strumentale a migliorare la funzione produttiva dei beni oggetto dell'iniziativa del singolo. Mortati ricordava il secondo comma dell'art. 42 sull'accessibilità a tutti della libertà privata; l'art. 43 sulle limitazioni tassative del sottrarre i beni ai singoli; l'art. 47 sulla proprietà abitativa e diretta coltivatrice. Indicava l'art. 44 come spinta per il legislatore, in nome della "coscienza collettiva del problema agrario", da combinare con l'art. 41 sulla proprietà privata, intesa come libertà d'iniziativa economica. La funzione sociale, esclusa dall'art. 838 del codice civile, pareva entrata nell'ordinamento con la Costituzione, innovativa per aver imposto ai proprietari di beni produttivi l'obbligo positivo di utilizzazione. Mortati ricordava che Fanfani aveva indicato al legislatore il compito di provvedere alla riforma agraria, nella sottolineatura del vincolo, per lo Stato, di ridisegnare la proprietà tramite Enti regionali di diritto pubblico, incaricati di assegnare le terre e indirizzare l'opera dei coloni, garanzia per le «mete indicate dalla Costituzione» ${ }^{166}$.

Nel primo Convegno internazionale di diritto agrario, promosso a Firenze da Bolla nel 1954, Il problema giuridico della terra risaltava in un'ampia prospettiva comparata, con la «proprietà fondiaria istituzione-cosa», «intesa sempre meno in senso individualistico, per il correlativo svilupparsi della proprietà sociale» ${ }^{167}$. Bassanelli marcava la distanza tra "diritto astratto, risultante dalle fonti», e "diritto vivente», indicando un contratto agrario come mezzo in capo all'agricoltore

\footnotetext{
${ }^{164}$ Natoli, 1954 pp. 872 ss.

165 Esposito, 1954, pp. 196 ss.

166 Mortati, 1954 pp. 262 ss.

${ }^{167}$ Bolla, 1954, p. 21; sulla proprietà terriera «istituzione tipica» cfr. Galloni, 1954, p. 250.
} 
non proprietario di avviare una propria impresa. Dal «lavoro fonte di proprietà della terra» derivavano taluni problemi «delicati»,

la partecipazione dei lavoratori all'impresa, il riordinamento dei consorzi, la trasformazione dei contratti agrari già in atto con accentuata tendenza a rafforzare il diritto del lavoratore (mezzadro, affittuario coltivatore diretto).

La "proprietà» pareva "garantita» dalla Costituzione e dal legislatore «solo quando è sorretta dal lavoro [e] vince sulla proprietà inerte» ${ }^{168}$.

\section{Appunti dalle lezioni di diritto agrario del professor Mario Bracci}

I dattiloscritti Appunti dalle lezioni di diritto agrario del professor Mario Bracci per I'anno accademico 1954-1955 erano raccolti dall'allievo Enzo Balocchi, a lungo docente di diritto amministrativo nella Facoltà giuridica senese. Bracci era anche relatore di Tesi di laurea sulla «riforma fondiaria italiana», sui Consorzi agrari, sul "fattore di campagna» ${ }^{169}$; gli Appunti riepilogavano le questioni giuridiche dell'agricoltura dal primo dopoguerra al decennio successivo alla riforma agraria. II docente esordiva con il presentare i «problemi di viva attualità », iscritti nell'ordine giuridico di un Paese dall'economia prevalentemente agricola. Interveniva sui nodi più dibattuti, a principiare dal "concetto di diritto agrario», di cui rivendicava almeno l'autonomia didattica ${ }^{170}$. Tra i contributi scientifici segnalava la "pregevole» Rivista di diritto agrario, i recenti Codice delle leggi agrarie di Maroi e Pastina, la Legislazione agraria italiana di Bolla e Giannattasio, il Codice agrario a cura di Bassanelli e Cicu, gli Atti del Terzo convegno nazionale di diritto agrario, quelli del Primo Convegno internazionale di diritto agrario. Tra le fonti Bracci indicava ancora la centralità della consuetudine, sottolineando la peculiarità della materia, in cui «non tanto le leggi contano quanto il costume e le forze reali, che stanno dietro ai vari interessi in contrasto»; da qui i dubbi sull'utilità di un eventuale «codice», inteso nei termini di «leggi generali contenenti principi fondamentali» ${ }^{171}$.

In merito alla natura pubblica o privata della disciplina, il docente affermava che alla struttura individualista della codificazione la bonifica integrale aveva aggiunto disposizioni in tema di proprietà fondiaria; il diritto agrario era stato 'attratto' nel diritto pubblico, oggetto della "attività dello Stato e degli enti pubblici nel settore economico sociale». La questione pareva peraltro complessa: ex art. 2135 del codice civile l'impresa agraria era indicata come il banco di prova della

168 Bassanelli, 1954, II, pp. 605 ss.

${ }^{169}$ Catoni, Leoncini, Vannozzi, 1990, p. 194.

${ }^{170}$ Bracci, 1954-1955 p. 3 ss. Sul dibattito intorno alla costruzione scientifica del diritto agrario, con metodo diverso dall'isolazionismo della civilistica cfr. Grossi, 1972, pp. 35 ss.; lannarelli,1999, pp. 631 ss.

${ }_{171}$ Bracci, 1954-1955, p. 40. Sul tema cfr. Cazzetta, 2003; sulla "genesi dal basso e fattualità» cfr. Grossi, 2019 p. XIII. 
coesistenza di «interessi privati e pubblici»; Bracci sosteneva inoltre che, accanto alla «disciplina della proprietà fondiaria, composta massimamente da norme di diritto privato", l'art. 44 della Costituzione "introduce e regola le norme di carattere pubblicistico a tutela degli interessi collettivi» ${ }^{172}$.

In prospettiva storica il docente indicava l'interesse della "storia degli usi civici»; spiegava che nel code civil la proprietà privata era stata disciplinata come diritto assoluto in reazione ai residui di feudalesimo; che era stata abolita poi dai "sistemi socialisti». Per Bracci gli artt. 41 e 44 della Costituzione avevano posto limiti alla estensione della proprietà terriera privata in vista della trasformazione del latifondo e ricostruzione delle unità produttive; una "proprietà dinamica» pareva aver "modificato in gran parte molte e radicate convinzioni del passato». Riguardo alla «nostra provincia» il docente asseriva, citando l'art. 44, che «il frazionamento estremo di una proprietà» non era adeguato alle "esigenze sociali». A proposito dei «limiti di diritto pubblico», posti nell'interesse della Pubblica amministrazione, Bracci si soffermava sulla espropriazione per pubblica utilità, «massima tra le limitazioni negative». Discutendo l'art. 838 del codice civile, il docente sosteneva che in certi casi l'epropriazione pareva assumere "funzione di sanzione sociale», «incomprensibile a chi fosse vissuto non molti anni orsono». Spiegava infatti che l'art. 48 della Costituzione aveva stravolto la logica della "Rivoluzione francese e dell'esasperato individualismo», configurando un "proprietario gestore nell'interesse nazionale». Bracci si chiedeva poi se quello posto alla proprietà fosse davvero un «limite»; con l'esempio della pensione al caduto in guerra - oggetto del suo studio del 1925 - ricordava che l'espropriato subiva la «dura realtà del diritto moderno [...] tutti gli interessi individuali possono essere sacrificati in funzione dell'interesse collettivo".

Il docente affrontava poi il tema dei modelli di proprietà, ricordando che lo Stato di polizia aveva ammesso la distinzione tra dominio eminente e dominio utile; che la Rivoluzione francese, in reazione agli «abusi», aveva sancito la «necessità pubblica, fondamento e causa dell'epropriazione». Affermava poi che nello "Stato e diritto moderno" - quelli dei suoi tempi, nell'accezione di Santi Romano - lo Stato era titolare della sovranità e che la proprietà di espropriare spettava solo alla Pubblica amministrazione. Ripercorreva la ratio dell'espropriazione, la «necessità assoluta» della Rivoluzione francese, l' «utilità pubblica» della legge del 1865 - «un fare o un non fare per pubblico interesse» - l'«interesse generale, cioè il benessere collettivo", riconosciuto dalla Costituzione. Bracci spiegava che il tema era di grande rilievo per le «leggi di riforma agraria», con la sottolineatura che, "come è noto, non esiste una legge di riforma agraria». In merito alla ratio delle «leggi attuali agrarie» citava «uno dei principali ispiratori e autore di queste leggi, Antonio Segni», assertore della centralità dell' «uomo, oggetto e soggetto della riforma agraria», di contro all'impostazione di chi considerava la terra «strumento puro e semplice di produzione». Bracci affermava che la «giu-

172 Bracci, 1954-1955, p. 11. 
stizia distributiva» era già «in nuce nello Stato di diritto», e che essa non doveva risolvere il "problema della disoccupazione» o della "fame di terra», ma "sostituire il sistema della indiscriminata proprietà individuale con la proprietà coltivatrice limitata».

Bracci confrontava poi leggi speciali, codice civile, Costituzione; sosteneva che l'art. 838 «teoricamente anticipava alcune disposizioni della attuale riforma agraria», a proposito del largo potere discrezionale della Pubblica amministrazione sulla «negligenza» del proprietario, usufruttuario, nudo proprietario; ricordava che il decreto era impugnabile presso il consiglio di Stato ${ }^{173}$. Il docente affrontava inoltre il tema della concessione delle terre incolte, oggetto delle «leggi speciali amministrative» dell'immediato dopoguerra, attente alla «profonda miseria dei coltivatori agricoli» ed all' «assentetismo dei proprietari», ed intese alla «realizzazione di più equi rapporti sociali e maggiore produttività della terra». Da un lato Bracci indicava i precedenti delle «leggi attuali agrarie» - l'istituzione dell'Opera nazionale combattenti, "legge venata di socialità», il Rdl 16 Settembre 1926, n. 1606 - dall'altro sottolineava che le «leggi di bonifica integrale emanate durante la dittatura avevano scopi ed interessi diversi dall'attuale ordinamento". Ricordava la tensione per un nuovo "elemento dell'ordinamento giuridico italiano", condizione di «pace sociale»,

un sistema che abbia al centro il coltivatore diretto di un'azienda familiare, unito in cooperativa con altri coltivatori, e sorretto ed aiutato per molti anni dallo Stato [...] cooperative ai contadini, limitazioni dei diritti e interessi individuali.

A dieci anni dalla Liberazione l'assetto delle campagne pareva però tornato al "pieno sistema di protezione senza limiti della proprietà individuale privata», con le «leggi di riforma agraria [...] allo stato fluido». Bracci descriveva dunque la legge per la Sila, la legge stralcio per le zone «particolarmente depresse, socialmente ed economicamente», la legge regionale della Sicilia del 27 Dicembre 1950. Metteva in evidenza lo scopo di trasformare e distribuire le terre, con l'espropriazione delle proprietà agrarie superiori ai 300 ettari, in virtù di un atto del governo, "con decreti che hanno valore di legge formale vera e propria». Ricordava anche il "dibattito ampio e vivace in dottrina», tra chi considerava i decreti atti amministrativi, impugnabili secondo la regola generale, come stabilito dal Consiglio di Stato, di contro al parere della Cassazione ${ }^{174}$. Bracci sottolineava che la legge stralcio non poneva il limite dei 300 ettari, col ricorso ad un limite qualitativo; ne spiegava la ratio, «il grande proprietario non può percepire dalla terra oltre un certo reddito». Argomentava che era "combattuto, come pericolo sociale, l'accentrarsi in poche mani del reddito e ricchezza agricola», con l'eccezione delle "aziende modello", "casi circoscritti»; aggiungeva che il proprietario espropriato doveva trasformare i terreni residui con l'indennità di scorporo. Bracci offriva

\footnotetext{
173 Ivi, p. 40.

${ }^{174}$ Ivi, p. 51 ss.
} 
poi dati sulla «portata sociale ed economica delle leggi di riforma agraria», l'espropriazione di circa 700 mila ettari, assegnati a 90 mila coltivatori diretti.

La "grave questione del frazionamento», all'origine del «problema della minima unità culturale ${ }^{175}$, pareva meritare una trattazione specifica. II docente sottolineava che l'art. 846 del codice civile sui trasferimenti di proprietà non aveva ammesso frazionamenti che non rispettassero l'«estensione del terreno necessario e sufficiente per il lavoro di una famiglia agricola»; e che, nel caso di terreno non appoderato, il frazionamento doveva consentire una conveniente coltivazione, secondo le regole della buona tecnica agraria. Bracci concludeva che non aveva trovato "pratica attuazione» l'incarico di determinare la minima unità, dato agli Enti di bonifica ed alla Pubblica amministrazione. Il docente illustrava poi gli artt. 850 e 851 - intesi a garantire un equilibrio tra le «esigenze pubblicistiche della produzione con quelle individuali delle singole proprietà» - e l'art. 852 , che escludeva dai trasferimenti coattivi case, terreni adiacenti, orti, terreni con «coltura a carattere di spiccata individualità».

Negli Appunti dalle lezioni il diritto agrario risaltava come un'esperienza giuridica complessa, con le norme in tema di proprietà fondiaria, contenute nel codice civile e nelle leggi speciali, rilette alla luce dello spirito della Costituzione; il legame 'terra-lavoro' - colto da Bracci come architrave della Carta - era vocato a «sostituire il sistema della indiscriminata proprietà individuale con la proprietà coltivatrice limitata». Esemplari le pagine sul tema centrale per il giurista senese, consapevole del fatto che l'efficacia della riforma agraria era rimessa soprattutto al funzionamento dei Consorzi, «una delle più importanti forme di associazione a fini produttivi di pubblico e privato interesse, diversa dalle società e cooperative». Il docente spiegava che il "fine fissato dalla legge è l'interesse collettivo, non il tornaconto individuale»; da qui la qualifica dei Consorzi come «persone giuridiche pubbliche», sotto il controllo statale, anche se costituiti da «privati» ${ }^{176}$.

\section{Fonti archivistiche}

ASS, Archivio Mario Bracci

AsuS, XII Bb 47, Mario Bracci, Fascicolo personale n. 1137

\section{Bibliografia}

Arcangeli A., 1936: Natura giuridica e problemi sindacali della mezzadria, in Id., Scritti di diritto commerciale ed agrario, III, Padova, Cedam

Ascarelli T., 1935: L'importanza dei criteri tecnici nella sistemazione delle discipline giuridiche e il diritto agrario, in Atti del primo Congresso Atti del Primo congresso

\footnotetext{
175 Ivi, p. 55.

${ }^{176}$ Ivi, p. 58.
} 
nazionale di diritto agrario, Firenze, Ricci

Ascheri M., 2011: La mezzadria tra città e campagna nella storia di Siena, in M. Ascheri, A. Dani, La mezzadria nelle terre di Siena e Grosseto dal medioevo all'età contemporanea, Siena, Pascal

Atripaldi M., 2020: La disciplina della proprietà terriera nell'art. 44 della Costituzione. Una ricostruzione dell'itinerario che ha determinato la formulazione della normativa costituzionale, in "Nomos. Le attualità del diritto"

Azzariti G., 1935: Per un'organica legis/azione agraria, in Atti del primo Congresso nazionale di diritto agrario, Firenze, Ricci

Azzariti G., 1954: Tecnica e sistematica della legislazione agraria, in S. Orlando Cascio (ed.), Atti del terzo congresso nazionale di diritto agrario, Milano, Giuffrè

Balzarini, R., 1939: Il concetto di proprietà nello Stato corporativo, in La concezione fascista della proprietà privata, Roma, Confederazione fascista dei lavoratori

Bandini M., 1960: La riforma fondiaria. 1950-1960, in I Piani di sviluppo in Italia dal 1945 al 1960, Presentazione di A. Fanfani, Milano, Giuffrè

Barassi L., 1939: Il diritto di proprietà e la funzione sociale, in La concezione fascista della proprietà privata, Roma, Confederazione fascista dei lavoratori

Bassanelli E., 1942 : I contratti agrari nel nuovo codice, in "Atti dei Georgofili"

Bassanelli E., 1948: La crisi del contratto agrario (a proposito del progetto Segni sulla riforma dei contratti agrari), in "Rivista di diritto agrario"

Bassanelli E., 1954: Struttura e funzioni del contratto agrario, in S. Orlando Cascio (ed.), Atti del terzo congresso nazionale di diritto agrario, Milano, Giuffrè

Bassanelli E., Il lavoro come fonte di proprietà della terra, in G. Bolla (ed.), Atti del primo convegno internazionale di diritto agrario, II, Milano, Giuffrè

Battaglia F., 1947: Proprietà fondiaria e riforma costituzionale dello Stato, in "Rivista di diritto agrario"

Bernardi E., 2008: La riforma agraria in Italia e gli Stati uniti. Guerra fredda, Piano Marshall e interventi per il Mezzogiorno negli anni del centrismo degasperiano, Bologna, II Mulino

Betti E., 1957: Lezioni di diritto civile sui contratti agrari, Milano, Giuffrè

Bindi E., 2015: Partito d'azione e processo costituente: il ruolo di Bracci e Calamandrei, in "Studi senesi"

Bindi E., 2016: Mario Bracci e la Corte costituzionale, in Scritti in onore di Gaetano Silvestri, I, Torino, Giappichelli

Bindi E, Colao F. (edd.), 2021: Piero Calamandrei. Dagli anni senesi all'attuazione della Costituzione, Napoli, Esi

Bolchini P., 2016: Silvio Trentin, Luigi Luzzatti e il riformismo istituzionale, in F. Cortese (ed.), Liberare e federare. L'eredità intellettuale di Silvio Trentin, Firenze, University press 
Bolla G., 1922: Programma della Rivista di diritto agrario, in "Rivista di diritto agrario"

Bolla G., 1931, Per la Raccolta delle consuetudini agrarie, in "Rivista di diritto agrario"

Bolla G., 1935: Il fondo nei suoi aspetti giuridici, in Atti del Primo Congresso nazionale di diritto agrario, Firenze, Ricci

Bolla G., 1937: Agricoltura, in Nuovo Digesto italiano, Torino, Utet

Bolla G., 1938: Contratto agrario, in Nuovo Digesto italiano, Torino, Utet

Bolla G., 1939: Prospettive sulla disciplina giuridica della proprietà fondiaria, in La concezione fascista della proprietà privata, Roma, Confederazione fascista dei lavoratori

Bolla G., 1942: Gli studi di diritto agrario in Italia nel ventennio fascista, in Bibliografie del ventennio. II pensiero giuridico italiano, Roma, Irce

Bolla G., 1943: La disciplina giuridica dell'agricoltura nel nuovo codice civile, in "Atti dei Georgofili"

Bolla G., 1949: L'art. 44 della Costituzione italiana e la sua interpretazione organica, in "Rivista di diritto agrario"

Bolla G., 1954a: Per un terzo Congresso, in S. Orlando Cascio (ed.), Atti del Terzo Congresso nazionale di diritto agrario, Milano, Giuffrè

Bolla G., 1954b: Della proprietà fondiaria agraria come situazione oggettiva e come istituzione tipica, in S. Orlando Cascio (ed.), Atti del Terzo Congresso nazionale di diritto agrario, Milano, Giuffrè

Bolla, G. 1963: Il problema giuridico della terra, in Id., Scritti di diritto agrario, III, Milano, Giuffrè

Barile, P.: 1959: Ricordo di Mario Bracci, in "Il Ponte"

Bracci M., Raselli A., 1937: Sul progetto preliminare del codice di procedura civile, in "Studi senesi"

Bracci M., 1941: Le questioni e i conflitti di giuridizione e di attribuzione nel nuovo codice di procedura civile, in "Rivista di diritto processuale civile"

Bracci M., 1945: II problema giuridico della terra, in "Il Ponte"

Bracci M., 1951: A proposito dello schema di legge generale sulla pubblica amministrazione, in "Studi senesi"

Bracci M., 1954-1955: Appunti delle lezioni di diritto agrario del professor Mario Bracci (raccolti dal dottor Enzo Balocchi), Siena, Università degli studi di Siena

Bracci M., 1961: La proposta nel diritto amministrativo, Firenze Le Monnier

Bracci M., 1981a: Pericuriosi in imbarazzo, in Id., Testimonianze sul proprio tempo. Meditazioni, lettere, scritti politici (1943-1958), E. Balocchi, G. Grottanelli de' Santi (edd.) Firenze, La nuova Italia 
Bracci M., 1981b: I fattori storici del fascismo italiano ed il loro superamento, in Id., Testimonianze sul proprio tempo. Meditazioni, lettere, scritti politici (19431958), E. Balocchi, G. Grottanelli de' Santi (edd.), Firenze, La nuova Italia

Bracci M., 1981c: Appunti sullo Stato, in Id., Testimonianze sul proprio tempo. Meditazioni, lettere, scritti politici (1943-1958), E. Balocchi, G. Grottanelli de' Santi (edd.), Firenze, La nuova Italia.

Bracci M., 1981d: Perchè i ministeri non funzionano, in Id., Testimonianze sul proprio tempo. Meditazioni, lettere, scritti politici (1943-1958), E. Balocchi, G. Grottanelli de' Santi (edd.), Firenze, La nuova Italia

Bracci M., 1981e: Aspetti pratici del problema regionale, in Id., Testimonianze sul proprio tempo. Meditazioni, lettere, scritti politici (1943-1958), E. Balocchi, G. Grottanelli de' Santi (edd.), Firenze, La nuova Italia

Bracci M., 1981f: Storia di una settimana (7-12 giugno 1946), in Id., Testimonianze sul proprio tempo. Meditazioni, lettere, scritti politici (1943-1958), E. Balocchi, G. Grottanelli de' Santi (edd.), Firenze, La nuova Italia

Bracci M., 1981g: Alla ricerca di un notaio o del custode della Repubblica?, in Id., Testimonianze sul proprio tempo. Meditazioni, lettere, scritti politici (19431958), E. Balocchi, G. Grottanelli de' Santi (edd.), Firenze, La nuova Italia

Bracci M., 1981h: Aspetti giuridici della corruzione politica, in Id., Testimonianze sul proprio tempo. Meditazioni, lettere, scritti politici (1943-1958), E. Balocchi, G. Grottanelli de' Santi (edd.), Firenze, La nuova Italia

Bracci M., 1981i, Per il IV anniversario della Repubblica, in Id., Testimonianze sul proprio tempo. Meditazioni, lettere, scritti politici (1943-1958), E. Balocchi, G. Grottanelli de' Santi (edd.), Firenze, La nuova Italia

Bracci M., 1981l: Celebrazione della Resistenza, in Id., Testimonianze sul proprio tempo. Meditazioni, lettere, scrittipolitici (1943-1958), E. Balocchi, G. Grottanelli de' Santi (edd.), Firenze, La nuova Italia

Bracci M., 1981m: Come è nata la Repubblica, in Id., Testimonianze sul proprio tempo. Meditazioni, lettere, scrittipolitici (1943-1958), E. Balocchi, G. Grottanelli de' Santi (edd.), Firenze, La nuova Italia

Bracci M., 1981n: Lettera a Giovanni Gronchi, Id., Testimonianze sul proprio tempo. Meditazioni, lettere, scritti politici (1943-1958), E. Balocchi, G. Grottanelli de' Santi (edd.), Firenze, La nuova Italia

Bracci M., 1981o: Un opuscolo per i contadini, in Id., Testimonianze sul proprio tempo. Meditazioni, lettere, scrittipolitici (1943-1958), E. Balocchi, G. Grottanelli de' Santi (edd.), Firenze, La nuova Italia

Bracci M., 1981p: Libertà e proprietà, in Id., Testimonianze sul proprio tempo. Meditazioni, lettere, scritti politici (1943-1958), E. Balocchi, G. Grottanelli de' Santi (edd.), Firenze, La nuova Italia

Bracci M., 2020: "Promemoria" alle autorità alleate, in Id., Carte sparse, Riflessioni, 
pagine di diario, relazioni, discorsi (1934-1945), Introduzione, edizione e note a cura di S. Moscadelli, Siena, Accademia degli Intronati

Branca G., 1960 : Ricordo di Mario Bracci, in "Studi senesi"

Brugi B., 1928: Per l'autonomia del diritto agrario, in "Rivista di diritto agrario"

Calamandrei P., 1935: Diritto agrario e processo civile. Comunicazione del Prof. Piero Calamandrei, in Atti del Primo Congresso nazionale di diritto agrario, Firenze, Ricci

Calamandrei P., 1952: Per i trent'anni della Rivista di diritto agrario, in "Rivista di diritto agrario"

Canguilhem C., 2007: Il fascismo e i contadini, Bologna, II Mulino

Capograssi G., 1952: Agricoltura, diritto, proprietà, in "Rivista di diritto agrario"

Cardini A., 2001: Mario Bracci. L'esordio dell'attività politica, in A. Cardini, G. Grottanelli De Santi (edd.), Mario Bracci nel centenario della nascita, Bologna, II Mulino

Cardini A., 2006: Introduzione. La fine dell'Italia rurale e il miracolo economico, in A. Cardini (ed.), Miracolo economico italiano, Bologna, II Mulino

Caretti P., 2013: La Costituzione ha ancora qualcosa da dire in un contesto globalizzato?, in G. Brunelli, G. Cazzetta (ed.), Dalla Costituzione "inattuata" alla Costituzione "inattuale". Potere costituente e riforme costituzionali nell'Italia repubblicana, Milano, Giuffrè

Carnelutti F., 1954: La via della salvezza, in S. Orlando Cascio (ed.), Atti del terzo congresso nazionale di diritto agrario, Milano, Giuffrè

Cazzetta, G., 2003: Natura delle cose e superbia del legislatore. Giuseppe Capograssi e il diritto agrario di metà Novecento, in "Rivista di diritto agrario"

Cesarini Sforza W., 1943: Proprietà e produzione nell'impresa agraria, in "Rivista di diritto agrario"

Chiarelli G., 1939: Il fondamento pubblicistico della proprietà, in La concezione fascista della proprietà privata, Roma, Confederazione fascista dei lavoratori

Cianferotti G., 2007a: Dottrine generali del diritto e lotta politica in Italia. II libro di Mario Bracci su «Le pensioni di guerra», in S. Pagliantini, E. Quadri, D. Sinesio (edd.), Scritti in onore di Marco Comporti, I, Milano, Giuffrè

Cianferotti G., 2007b: Gli scritti di Mario Bracci sulla proposta e l'atto complesso in diritto amministrativo, in A. Pisaneschi, L. Violini (ed.), Poteri, garanzie e diritto a sessant'anni dalla Costituzione. Scritti per Giovanni Grottanelli de' Santi, Milano, Giuffrè

Cianferotti G., 2008: Ufficio del giurista nello Stato autoritario ed ermenutica della reticenza. Mario Bracci e Piero Calamandrei: dalle giurisdizioni di equità della grande guerra al codice di procedura civile del 1940, in "Quaderni fiorentini per la storia del pensiero giuridico moderno" 
Cianferotti G., 2013: Bracci, Mario, in Dizionario biografico dei giuristi italiani (XIXX secolo), diretto da I. Birocchi, E. Cortese, A. Mattone, M.N. Miletti, Bologna, II Mulino

Cianferotti G., 2015: L'opera giuridica di Mario Bracci tra le due guerre, in "Studi senesi"

Colao F., 2014: I giuristi universitari a Siena tra diritto e politica (1938-1958), in M. Cavina (ed.), Giuristi al bivio. La Facoltà di giurisprudenza tra regime fascista ed età repubblicana, Bologna, Clueb

Colao F., 2015: Mario Bracci giurista civile al bivio, in "Studi senesi"

Commissione di studi giuridici della Confederazione nazionale fascista degli agricoltori, 1930: Schema di norme per il riordinamento della proprietà fondiaria, Roma-Milano, Bestetti Tumminelli

Costato L., 2013: Maroi, Fulvio, in Dizionario Biografico dei giuristi italiani (XI-XX secolo), diretto da I. Birocchi, E. Cortese, A. Mattone, M.N. Miletti, Bologna, II Mulino

Costato L.: 2013, Bolla, Giangastone, in Dizionario biografico dei giuristi italiani (XI-XX secolo), diretto da I. Birocchi, E. Cortese, A. Mattone, M.N. Miletti, Bologna, II Mulino

Cova A., 1993: I cattolici e la questione agraria, (1874-1950), Roma, Studium

D’Alessio G. (ed.), 1979: Alle origini della Costituzione italiana. I lavori preparatori della Commissione per gli studi attinenti alla riordinazione dello Stato (19451946), Bologna, II Mulino

D’Amelio M., 1935; Le consuetudini e il diritto dello Stato, in "Rivista di diritto pubblico"

De Felice R., 1961: Mussolini il fascista. La conquista del potere 1921-1925, Torino, Einaudi

De Luna G., 1997: Storia del Partito d'azione. 1942-1947, Roma, Editori riuniti

Dell'Angelo G., 1946: Il problema agrario, Roma, Ministero della Costituente

Di Sandro G., Monti A., 2020: /l Papa laico: Arrigo Serpieri fra storia politica ed economia agraria. Dalla contrattualistica agraria alla bonifica integrale, Milano, Angeli

Di Sandro, G. 2015: Arrigo Serpieri: tra scienza e praticità di risultati. Dall'economia agraria alla bonifica integrale per lo sviluppo del paese, Milano, Angeli

Einaudi L., 1956: Lo scrittoio del presidente, Torino, Einaudi

Esposito C., 1954: Note esegetiche all'art 44 della Costituzione, in Id., La Costituzione italiana. Saggi, Padova, Cedam

Ferrara F., 1939: La proprietà come «dovere sociale», in La concezione fascista della proprietà privata, Roma, Confederazione fascista dei lavoratori

Ferri G. B. 2013: Vassalli, Filippo, in Dizionario biografico dei giuristi italiani (XI-XX 
secolo), diretto da I. Birocchi, E. Cortese, A. Mattone, M.N. Miletti, Bologna, II Mulino

Finzi E., 1935: Diritto di proprietà e disciplina della produzione, in Atti del Primo congresso nazionale di diritto agrario, Firenze, Ricci

Finzi E., 1923: Le moderne trasformazioni del diritto di proprietà, in "Archivio giuridico"

Fioravanti M., 2013: Mortati, Costantino, in Dizionario Biografico dei giuristi italiani (XI-XX secolo), diretto da I. Birocchi, E. Cortese, A. Mattone, M.N. Miletti, Bologna, II Mulino

Funaioli G. B., 1939 : I miglioramenti fondiari e la funzione sociale della proprietà, in La concezione fascista della proprietà privata, Roma, Confederazione fascista dei lavoratori

Funaioli G. B., 1942: L'impresa agraria nel libro del lavoro, Pisa, Pacini e Mariotti

Galloni G., 1954: Proprietà e destinazione fondiaria in G. Bolla (ed.), Atti del primo convegno internazionale di diirtto agrario, Milano, Giuffrè

Gatti S., 1939 : Dalla concezione individualistica alla concezione fascista della proprietà privata, in La concezione fascista della proprietà privata, Roma, Confederazione fascista dei lavoratori

Gentile S., 2018: Di alcune carte inedite di Giangastone Bolla. Un'occasione di riflessione circa il rapporto tra giuristi e il regime fascista, in "Ius. Vita e pensiero"

Giuffrida M., 2019, Proprietà agraria e costituzione, (note a margine di una legge e di un disegno di legge), in E. Cristiani, A. Di Lauro, E. Sirsi (edd.), Agricoltura e Costituzione. Una costituzione per l'agricoltura, Pisa, University press

Grossi P., 1972: II momento storico-giuridico nella elaborazione dottrinale dell'autonomia del diritto agrario, in "Rivista di diritto agrario"

Grossi P., 2000: Scienza giuridica italiana. Un profilo storico (1859-1950), Milano, Giuffrè

Grossi P., 2002: Presenze vigili: Salvatore Pugliatti, un civilista inquieto, in Id., La cultura del civilista italiano, Milano, Giuffrè

Grossi P., 2008a: Un giurista solitario: Enrico Finzi, in Id. Nobiltà del diritto, Profili di giuristi, Milano 2008

Grossi P., 2008b: L'itinerario scientifico di Enrico Bassanelli, in Id., Nobiltà del diritto, Profili di giuristi, Milano, Giuffrè

Grossi, P., 2016, Fattualità del diritto pos-moderno: l'emersione del diritto "agrario" in Italia, in "Diritto agroalimentare"

Grossi P., 2019, Prefazione a S. Masini, «Tracce» di diritto agrario, Bari, Cacucci

lannarelli A., 2001: L'imprenditore agricolo e le origini del libro V del codice civile, in "Quaderni fiorentini per la storia del pensiero giuridico moderno"

lannarelli A., 1999: La cultura agrarista tra codificazione e costituzione (1935- 
1952), in "Quaderni fiorentini per la storia del pensiero giuridico moderno" Irti N.: 2002, Scuole e figure del diritto civile, Milano, Giuffrè

La Consulta nazionale. 25 Settembre 1945-I Giugno 1946, Roma, Senato della Repubblica, 1948

La Costituzione della Repubblica nei lavori preparatori dell'Assemblea costituente, Roma, Camera dei deputati, 1970-1971

Landi G., 1954: Sul massimo impiego dei lavoratori in agricoltura, in S. Orlando Cascio (ed.), Atti del terzo congresso nazionale di diritto agrario, Milano, Giuffrè L'Archivio storico dell'Università di Siena, G. Catoni, A. Leoncini, F. Vannozzi (edd.), Roma, Pubblicazioni degli archivi di Stato, 1990

Leicht P.S., 1939: La proprietà fondiaria e lo stato della tradizione italiana, in La concezione fascista della proprietà privata, Roma, Confederazione fascista dei lavoratori

Lessona S., 1954: Decadenza delle concessioni di terre incolte, in S. Orlando Cascio (ed.), Atti del terzo congresso nazionale di diritto agrario, Milano, Giuffrè

Macario F., Miletti M.N., 2015: La funzione sociale nel diritto privato tra XX e XIX secolo, Roma University press

Maiorca C., 1934: Lo spazio e i limiti della proprietà fondiaria, Torino, Istituto giuridico dell'Università

Maroi F., 1935: La storia del diritto agrario e i suoi insegnamenti, in Atti del primo Congresso nazionale di diritto agrario, Firenze, Ricci

Maroi F., 1942a: Il primo ventennio di vita della Rivista di diritto agrario, in "Rivista di diritto agrario"

Maroi F., 1942b, L'agricoltura nel libro $V$ del nuovo codice civile, in "Atti dei Georgofili"

Mattone A., 2016: Il ministro Antonio Segni «agrarista». Politica e scienza giuridica nell'elaborazione della riforma agraria e della legge sui contratti agrari (19461950), in "Studi storici"

Ministero della Costituente, 1947: Rapporto della Commissione economica, I, Roma, Istituto poligrafico dello Stato

Misiani S., 2018: Serpieri, Arrigo, in Dizionario Biografico degli Italiani, Roma, enciclopedia italiana

Mortati C., 1947: Indirizzi costituzionali nella disciplina della proprietà fondiaria, in "Rivista di diritto agrario"

Mortati C., 1954: La Costituzione e la proprietà terriera, in S. Orlando Cascio (ed.), Atti del terzo congresso nazionale di diritto agrario, Milano, Giuffrè

Moscadelli S., 2019: Mario Bracci allo specchio delle sue carte, in "Bullettino senese di storia patria" 
Mura S., 2017: Antonio Segni. La politica e le istituzioni, Bologna, II Mulino

Natoli U., 1954: La posizione giuridica degli assegnatari di terre "scorporate" e la prassi degli enti di riforma, in S. Orlando Cascio (ed.), Atti del terzo congresso nazionale di diritto agrario, Milano, Giuffrè

Panunzio S., Prime osservazioni giuridiche sul concetto di proprietà nel regime fascista, in La concezione fascista della proprietà privata, Roma, Confederazione fascista dei lavoratori

Passaniti P.: 2017: Mezzadria. Persistenza e tramonto di un archetipo contrattuale, Torino, Giappichelli

Pugliatti S., 1935: Interesse pubblico e interesse privato nel diritto di proprietà, in Atti del Primo congresso nazionale di diritto agrario, Firenze, Ricci

Pugliatti, S., 1939: Strumenti tecnico-giuridici per la tutela dell'interesse pubblico nella proprietà, in La concezione fascista della proprietà privata, Confederazione fascista dei lavoratori, Roma

Pugliatti S., 1954a: La ricomposizione delle proprietà frammentate secondo le nuove norme sulla bonifica integrale; l'occupazione e amministrazione coattiva delle terre incolte, in Id., Scritti giuridici, III, Milano, Giuffrè

Pugliatti S., 1954b: La definizione della proprietà nel nuovo codice civile, in Id., La proprietà nel nuovo diritto, Milano, Giuffrè

Pugliatti S., 1954c: La proprietà e le proprietà, con particolare riguardo alla proprietà terriera, in S. Orlando Cascio (ed.), Atti del Terzo Congresso nazionale di diritto agrario, Milano, Giuffrè

Putzolu A., 1942a: L'impresa agraria nel codice civile fascista, in "Rivista di diritto agrario"

Putzolu A. 1942b: La nuova disciplina giuridica dell'impresa e dei rapporti agrari alle luce delle idee della Rivoluzione, in "Atti dei Georgofili"

Raselli A., 1962: I/ ricordo di Mario Bracci in Pontignano, Terra di Siena, Siena

Rescigno P., 2006: Proprietà fondiaria e 'patti agrari' nell'opera di Antonio Segni, in M. Brigaglia (ed.), Per una storia della riforma agraria in Sardegna, Roma, Carocci

Rivalta M., 1954: La funzione sociale della proprietà terriera nella Costituzione, in S. Cascio (ed.), Atti del terzo congresso nazionale di diritto agrario, Milano, Giuffrè

Rodotà S., 1982: Commento all'articolo 44, in G. Branca (ed.), Commentario alla Costituzione, Bologna-Roma, Zanichelli.

Rodotà S., 2011: Diritti e libertà nella storia d'Italia. Conquiste e conflitti (18612001), Roma, Donzelli

Rondinone N., 2020: Impresa e commercialità attraverso il "lato oscuro" dell'unificazione dei codici, Torino, Giappichelli 
Rossi Doria M., 1956a: Alle origini della legge sulle trasformazioni fondiarie, in Riforma agraria e azione meridionalista, Bologna, Edizioni agricole

Rossi Doria M., 1956b: I problemi delle trasformazioni fondiarie nel Mezzogiorno e nelle isole, in Riforma agraria e azione meridionalista, Bologna, Edizioni agricole

Rossi Doria M., 1956c: L'individuazione delle proprietà e i problemi tuttora aperti della bonifica del Mezzogiorno, in Riforma agraria e azione meridionalista, Bologna, Edizioni agricole

Rossi Doria M., 1956d: La situazione delle campagne italiane, in Id., Riforma agraria e azione meridionalista, Bologna, edizioni agricole

Rossi Doria, M., 1956e: Problemi, conflitti e politica nel 1947, in Id., Riforma agraria e azione meridionalista, Bologna, edizioni agricole

Rossi Doria M. 1958: II professor Ammazzagatti, in Id., Dieci anni di politica agraria nel Mezzogiorno, Bari, Laterza

Rossi E., 1945 : La riforma agraria, Milano, La fiaccola

Santoro Passarelli F., 1935 : Locazione e affitto rustico, in Atti del Primo Congresso nazionale di diritto agrario, Firenze, Ricci

Santoro Passarelli F., 1954: Proprietà e lavoro in agricoltura, in S. Orlando Cascio (ed.), Atti del Terzo Congresso nazionale di diritto agrario, Milano, Giuffrè

Segni, A.: 1954a: La riforma fondiaria in Italia, in G. Bolla (ed.), Atti del Primo Convegno internazionale di diritto agrario, I, Milano, Giuffrè

Segni A., 1954b, Struttura della proprietà fondiaria, in G. Bolla (ed.), Atti del Primo Convegno internazionale di diritto agrario, I, Milano, Giuffrè

Sereni E., 1946: La questione agraria nella rinascita nazionale italiana, Torino, Einaudi

Serpieri A., 1922: Osservazione sul disegno di legge trasformazione del latifondo e colonizzazione interna, Piacenza, Federconsorzi

Serpieri A., 1925: La politica agraria in Italia e i recenti provvedimenti legislativi, Piacenza, Federazione italiana dei Consorzi agrari

Serpieri A., 1927a: Passato e avvenire dell'Accademia dei Georgofili. Discorso inaugurale del presidente tenuto nel Salone dei Dugento in Palazzo vecchio, in Atti dei Georgofili

Serpieri A., 1927b: La proprietà fondiaria nel regime fascista, in Atti dei Georgofili.

Serpieri A. 1934: Fra politica ed economia rurale, Firenze, Barbera.

Serpieri A. 1937: La bonifica integrale, Pavia, Tip. Fratelli Fusi.

Serpieri A., 1947: La bonifica nella storia e nella dottrina, Bologna, edizioni agricole

Serpieri A., 1957: Scritti di economia agraria. 1946-1953, Firenze, Le Monnier 
Sommaruga R., 1944: Cosa vogliono i partiti?, Roma, editoriale romana

Stolzi I., 2007: L'ordine corporativo. Poteri organizzati e organizzazione del potere nella riflessione giuridica dell'Italia fascista, Milano, Giuffrè

Taviani P. E., 2002: Politica e memoria d'uomo, Bologna, II Mulino

Tavilla E., 2004: Pubblico e privato nell'opera di bonifica: I'istituto consortile in Italia tra Otto e Novecento, in "Forum Historiae Iuris"

Vassalli F., 1923: Le riforme del codice civile in relazione alla proprietà fondiaria, in Id., Scritti giuridici, II, Milano, Giuffrè

Vassalli F., 1939: Per una definizione legislativa del diritto di proprietà, in La concezione fascista della proprietà privata, Roma, Confederazione fascista dei lavoratori

Vassalli F., 1949: Sul disegno di legge $n .175$ del 1948 contenente disposizioni sul contratto di mezzadria, in "Rivista di diritto agrario"

Vivarelli R., 2008: Fascismo e storia d'Italia, Bologna, II Mulino 